Homocysteine in Neurology: A Risk Factor or Something Different in Small Vessel Disease

Rita Moretti, Paola Caruso, Silvia Gazzin ${ }^{1}$ and Claudio Tiribelli

Dpt. Medical, Surgical and Health Sciences, University of Trieste

Italian Liver Foundation, FIF; SCIENCE PARK, Trieste

Homocysteine (Hcy) is a sulfur-containing amino acid that is generated during methionine metabolism. Hyperhomocysteinemia (HHcy) is typically defined as levels $>15$ micro mols/L. Elevated plasma levels of Hcy can be caused by the deficiency of either vitamin B12 or folate. The active role of homocysteine is quite ambivalent: many studies detected its potential impact on neurological events; others try to identify it as one of the possible risk factors of cardiovascular events, but with a complementary and secondary role. HHcy has been reported in many neurologic disorders, including cognitive impairment and stroke, independent of long-recognized factors such as hyperlipidemia, hypertension, diabetes mellitus, and smoking. Nowadays, homocysteine could be considered as a possible link between a common vascular risk factor and potential alterations in degenerative neuronal disorders. HHcy-induced oxidative stress, endothelial dysfunction, inflammation, smooth muscle cell proliferation, and endoplasmic reticulum stress; all these aspects have been considered to play an essential role in the pathogenesis of several diseases, including atherosclerosis, major stroke, and vascular dementia. Specific models of astrocytes impairment in HHcy-mice, which mimic small vessel disease, have been developed with a three-step investigation (at 6, 10, 14 weeks of B6, B9, and B12 detrimental diet in wild type HHcy mouse). These studies found out that after ten weeks on a diet (at the most after 14 weeks), end-feet disruption occurs. This phenomenon is concomitant to reduced vascular labeling for aquaporin -4-water channels, lower protein/mRNA levels for Kir4.1, and BK potassium channels, associated with a higher expression of MMP-9. The most exciting finding is that microglial activation in this mice model was evident since the precocious time of observation (6-week time) and precedes astrocytic changes. Our research aims to review the possible role of HHcy in neurodegenerative disease and smallvessel disease and to understand its pathogenic impact. 


\section{Cerebral small vessel disease}

Cerebral small vessel disease (SVD) primarily distresses the small perforating arteries, defined as vessels with less than $50 \mu \mathrm{m}$ diameters, supplying the deep brain structures and the leptomeningeal space [1,2]. It is tightly related to general increased arterial stiffness and is the most important and common cause of vascular dementia, leading to $45 \%$ of dementia, and accounts for about $20-30 \%$ of all stroke worldwide, $25 \%$ of ischemic (or lacunar strokes). Moreover, it significantly increases the risk of future stroke [3, 4, 5]. Moreover, there is a consensus in the extension of the pathological target from small perforating arteriole towards the perivascular spaces (PVS) (usually a virtual space, where the pericyte membrane fuse together)[6,7], that act as a canal for the exchange between cerebrospinal fluid (CSF), and interstitial fluid (ISF) and for the clearance of catabolites [6], a so-called 'paravascular' or 'glymphatic' space [7,8, 9]. The significant consequences of their enlargement and disruption are the accumulation of catabolites and toxic substances, together with a pronounced neural starvation $[9,10]$. The immobility of the fluid drainage can support PVS's role in different diseases: the possible explanation of the PVS involvement in SVD is the argued relationship demonstrated between an altered cerebrovascular reactivity, which is the change in cerebral blood flow in response to a vaso-active stimulus in the so-called neurovascular coupling [11, 12]. In SVD, we observe too the occlusion of deep periventricular-draining veins [13], associated with the disruption of the blood-brain barrier (BBB). All these facts together lead a consequent leakage of fluid and plasma cells, which eventually might potentiate the perivascular inflammation, and all the cascades of the inflammatory/obstructive/stagnation-induced process $[11,14,15,16]$.

Above all these new aspects, the pathological expression of SVD is the arteriolosclerosis process $[8,17,18$, 19]. The loss of arterial elasticity and the consequent reduction of arterial compliance [20] are the primary determinant of the altered autoregulation capacities, leading to the brain of SVD patients' profound sensitiveness decreases of blood pressure $[21,22,23]$. The primary site of pathological localization is the subcortical infarcts, white matter hyperintensities, lacunes, prominent perivascular spaces, and cerebral microbleeds (visible in a conventional MRI) [24, 25], localized in the deep white matter capsule, along with the frontal and prefrontal-thalamus-basal forebrain networks, [26, 27], the caudate nucleus (the most precociously affected region), the putamen, insula, precentral gyrus, inferior frontal gyrus, and middle frontal gyrus.

Moreover, a low-level functioning of the autonomic nervous system has been observed, with direct and endothelium-mediated altered baroreflex activity [28,29,30,31]. Finally, SVD could affect the medial cholinergic pathway's integrity, for the hypoperfusion preferred localization, in the deep white matter capsule [32], or due to the multiple lacunar infarcts, the basal forebrain cholinergic bundle could be deafferentated from the tubero-mamillary tracts $[33,34]$. These aspects affect the normally-accurate cerebral flow regulation and can further disturb the "retrograde vasodilatation system" with necessary consequences in neurovascular coupling [35]. Moreover, SVD is characterized by an associated hypoperfusion progression, causing incomplete ischemia of the deep white matter [36, 37, 38, 39] accompanied by inflammation, diffuse rarefaction of myelin sheaths, axonal disruption, and astrocyte gliosis [8]. SVD could affect the integrity of the medial cholinergic pathway, for the hypoperfusion preferred localization, in the deep white matter capsule, [32], or due to the multiple lacunar infarcts, the basal forebrain cholinergic bundle could be deafferentated from the tubero-mamillary tracts $[33,34]$. These aspects affect the normally-accurate cerebral flow regulation and can further disturb the "retrograde vasodilatation system" with necessary consequences in neurovascular coupling [8].

Moreover, SVD is characterized by an associated hypoperfusion progression, causing incomplete ischemia of the deep white matter [36, 37, 38, 39] accompanied by inflammation, diffuse rarefaction of myelin sheaths, axonal disruption, and astrocyte gliosis [35]. In small vessel disease, occlusion of deep periventriculardraining veins is also evident [13], together with a disruption of the blood-brain barrier; the two factors are together causing a severe leakage of fluid and plasma cells to potentiate the inflammatory cascade, which seems to happen in the course of chronic hypoperfusion, collecting multifactorial causes for white matter alterations $[14,15,16]$. Cerebral small vessel disease is what has been described as "a progressive disease" [8]. Lesions progress over time, and the long-term outcome and impact on brain damage vary, even not knowing why or how; reasonably, it should be said that the most rapid and confluent progression of the isolated 
white matter hyperintensities could be considered as the most relevant predictor, at the best of knowledge, of the fatal progression of SVD [40,41, 42,43]. Of course, the total amount of lacunes and the profound white matter alterations relate to the degree of cognitive impairment $[44,45,46]$. The lesions' preferred location is placed along with the frontal and prefrontal-thalamus-basal forebrain networks [26, 27], directly implying the so-called cortical-deafferentation.

Additionally, lesions due to SVD are specific to the caudate nucleus (the most precociously affected region), the putamen, insula, precentral gyrus, inferior frontal gyrus, and middle frontal gyrus. The pathology has been fully explained by the higher metabolic request of these regions (more than 20\%) at steady state than other brain areas $[47,48,49,50,51,52,53,54]$. Arteriolosclerosis occurs in two primary histological forms: hyperplastic and the hyaline arteriolosclerosis $[55,56]$. The hyperplastic is the most common lesion, principally due to the chronic state of hypertension. It begins with the hypertrophy of the smooth muscle in the media, and it is accompanied by the reduplication of elastic laminae, the growth of new cells in the intima, and the deposition of collagen, which progressively substitutes the muscle cells (onion skin arteries), and severely obliterate the lumen [55]. Hyaline sclerosis is another change in hypertensive patients' vessels: the vessel wall becomes thickened with collagen [57, 58]. The hyaline material is a consequence of the leakage of the plasma proteins, mainly the inactive form of complement $(\mathrm{C} 3 \mathrm{~b})$ through the endothelium, and also by an increment of the basement membrane components by the smooth muscle cells [58]. Healthy aging implies the loss of the Windkessel effect, the loss of arterial elasticity, revealing an anticipated and precocious return of the so-called wave reflection. Healthy aging also determines an increase of the systolic and a decrease of diastolic pressure, with a loss of resting flow effect through the Willis, which decrements the usual high perfusion pressure towards the most profound small arteries of the brain [59, 60, 61], provoking a loss of brain flow autoregulation. This aging effect is amplified in SVD.

Arteriolosclerosis perpetuates the hypo-perfusion in the profound territories irrigated by penetrating arteries. Chronic ischemia determines a severe oligodendrocyte degeneration; soon after, it causes microglial activation and is further associated with an increase of apoptosis processes associated with an elevation of caspase 3 RNA and matrix- metalloprotease 2 (MMP-2) expression [62, 63]. Astrocytes react to the chronic ischemic condition as a result of the length and severity of the insult. In the early ischemic period, the astrocytes respond with a remarkable proliferation. In persistent hypoperfusion, with their degeneration and death $[64,65,66,67,68]$. Astrocytic death, due to chronic hypoperfusion, leads to an expanding and autopotentiating system of neuronal death, due to a misleading neurovascular coupling.

Moreover, small arteries undergo a systemic poorness of cholinergic network regulation. Many hypothesis have been raised for a possible explanation, starting from an altered cholinergic response to inflammation, which is a constant in chronic ischemic condition [69, 70,71,72], up to a disruption of the cholinergic networks, which subcortically approaches the basal forebrain, since this is a preferential location of lacunar vascular infarcts and chronic hypoperfusion syndrome [73, 74,75,76]. Chronic reduction of the cerebral blood flow can affect the control of the cholinergic networks, but it happens that a proper cholinergic function is compulsory to well-regulation of the regional brain blood flow [77, 78]. In animal SVD models, there is a concomitant reduction of vasopressin and histamine, interpreted as a result of the tracts' interruption, which comes from the supra-optic and tuberomammillary nuclei and ends in the basal forebrain [79]. It has been conveyed that the cholinergic impairment is not mediated by a direct loss of the cholinergic neurons of Nucleus Basalis of Meynert [80, 81], but is a consequence of the secondary cholinergic deficits due to the indirect, cholinergic endothelial effect, aforementioned. Nevertheless, the number of muscarinic cholinergic receptors is markedly reduced in mixed dementia patients [81] and SVD dementia. Cholinergic poorness promotes a less efficacious endothelium relaxation, even due to an altered nitric oxide synthase and loss of efficacy of the GABA interneurons [82, 83].

The pathological cascade of events, which occurs as a consequence of all the pathological alterations described, determines a decrease of the vascular tone, with a release of the blood-brain barrier permeability, with a loss of the internal vascular remodeling, and with major vascular rarefactions. As a result, hypoperfusion at rest occurs in the brain and is associated with an impairment in the moment-to-moment control of CBF. There is also a decrease in adaptive vascular responses and the diminishment of the neurovascular coupling and auto-regulation system [76,84]. 
Even if the endothelium is one of the main targets of the redox altered process and inflammation (and both these processes are highly activated in SVD), the brain endothelium, even in severe SVD (presenting an almost complete loss of myocytes and other mural cells) remains intact [85, 86, 87, 88]. This paradoxical survival of the brain endothelium is also evident in patients with CADASIL [85, 86]. On the contrary, systemic endothelium activation is quite different in SVD.

Thus, indirectly, brain endothelium suffers in SVD conditions. Mitochondrial senescence of the endothelium walls has a catastrophic effect on cerebral endothelial cells [89]; this alteration, which is over-expressed in SVD [90], is generally related to an impaired response to the three major endothelium-derived nitric oxidevasodilators [91], prostacyclin [92] and endothelium-derived hyperpolarizing factors (EDHF) [93]. The reduction of $\mathrm{NO}$ production is derived from an impairment of the mitochondrial functions, caused by a hyperproduction of the anti-oxidative defense system, and an increased $\mathrm{O} 2$ anions reaction with NO, producing peroxynitrite [94]. The activity of endothelial NO synthase (eNOS), which catalyzes the production of NO, declines with aging [95] but is even more impaired in SVD, where an important downstream target of Rho is the Rho-associated protein kinase (ROCK) [96]. These ubiquitously expressed serine/threonine protein kinases are involved in diverse cellular activities, including apoptosis, smooth muscle contraction, cell adhesion, and remodeling of the extracellular matrix [97]. In the regulation of endothelial cell, migration ROCK interacts with ezrin, radixin, and moesin, also known as the ERM proteins that function as cross-linkers between the plasma membrane and actin filaments [96], and are indispensable for the leukocyte adhesion molecules coordination, essential for barrier function [98]. Moreover, the ROCK/RhoA complex regulates, as previously exposed, the endothelial nitrous oxide synthase (eNOS) [96]. Nitric oxide (NO)-induced vasodilation occurs via myosin light chain phosphatase (MLCP) activation in a cGMP dependent manner. RhoA/ROCK counteracts this through MLCP inactivation and calcium desensitization [96, 99]. ROCK/Rho decreases eNOS expression and affects the availability of nitric oxide (NO) [100]; even if these effects have been largely studied in major vessel disease (coronary), it has also been proven in brain small vessels [8]. Three potentially functional eNOS polymorphisms (T-786C, intron 4ab, G894T) located toward the 5 ' flanking end of the gene are known to be considered as being present in SVD and also in isolated lacunar infarction and ischemic leukoaraiosis [101]. RhoA inhibition overwhelms vascular endothelium growth factor (VEGF)-enhanced endothelial cell migration in response to vascular injury, without, or better said, with minimal effect, on basal endothelial cell migration [102, 103]. The endothelial barrier's maintenance is a prior role of the endothelium cells, mainly through the operative system of RhoA [104], also mediated through the regulation of VE-cadherins [105]. In diabetes (one of the main risk factors associated to SVD), advanced glycation end products (AGEs) accumulate in the vasculature, triggering a series of purposeful and morphologic changes of endothelial cells, such as the increase of the activation of the RhoA/ROCK pathway; the significant consequence is an increased endothelial cell permeability [106]. It can also act as a VEGF inducer, which indirectly causes microvascular endothelial hyper-permeability [107].

Therefore, it should be argued that, even if morphologically and structurally undamaged, the endothelium seems to be functionally impaired in SVD [108].

The endothelial NO downregulation in SVD is a marker of decreased endothelial regulatory capacity, in response to external stimuli, such as hypercapnia [109, 110]. Living studies have demonstrated a significant baseline CBF reduction in SVD -affected subjects, together with an impaired CBF autoregulation [111,112, 113]. Endothelial activation refers to the change in many different surface markers [114, 115, 116, 117]. These circulating markers of endothelial activation include intercellular adhesion molecule-1 (ICAM-1), which has been considered as a generic expression of white matter progression [118], soluble thrombomodulin (sTM), interleukin-6 (IL-6), plasminogen activator inhibitor-1 (PAI-1), von Willebrand factor, and others [86, $119,120,121]$. Moreover, upregulation of hypoxia-endothelial-related markers has been proven, such as HIF 1 alpha, VEGFR2, and neuroglobin, when white matter lesions appear to be confluent [122]. The matter is even more impressive when it appears evident that endothelium in overall activated, as above described, but, according to some authors, not specifically in the human gray matter [88, 120, 123, 124]. Though, the brain endothelium NO dysregulation implies not only a direct inhibition of the vessel tone but indirectly, more critical, a decrease of the dynamic neurovascular control mechanism [125, 126]. 
Moreover, it should be taken into account the permanent status of oxidative stress-induced, which causes a superimposed macroscopic alteration of the cerebral endothelium.

The immediate consequence of the endothelial dysfunction has two significant consequences, the reduction of the resting flow in the marginally perfused white matter and macroscopic alterations of the BBB permeability [126]; these two aspects lead to additional oxidative stress by inducing tissue hypoxia and extravasation of the plasma proteins [126], and both of them potentiate inflammation pathway, through NFkBeta dependent transcription. The modern view gives the endothelium the control role of propagating vasomotor signals [127] even if the question is still unresolved. In systemic vessels, the endothelium is well known to participate in the retrograde propagation of vascular signals [7, 128], but in the brain, the mechanisms by which endothelium interacts with the spread of the vascular signal is still debated. It has been proven that a highly localized lesion of the endothelium failed to propagate beyond the lesion site, and altered the amplitude and the temporal dynamics of the go-ahead vascular sign, with weaker temporal coordination [129]. It has been demonstrated that brain endothelium is enriched with KIR channels, and not by KCa channels. These channels are sensitive to high $\mathrm{K}$ flow, derived from neural activity, and transmitted by the synapses or astrocytic end-feet [128,130]. K+ is recognized in the endothelium, and the upstream penetrating arteriole is the effector of the vasodilatation [130]. Its rapid propagation is probably conducted by ionic currents traveling through the endothelium via gap junctions and then through the myoendothelial junctions [128]. Therefore, a KIR suppression avoids the increase of CBF produced by cortical activation [130]. The most intriguing aspect of the endothelial conductance is that the conducted vasomotor responses, either being a dilatation or vasoconstriction, can be generated by different neuromodulators, ie. Acetylcholine, ATP, prostaglandin F2alpha, NO, but their effects on neurovascular coupling has never been determined [131]. The evidence is increasing on pial arterioles: signals generated by the neuronal activity, deep in the brain, should be conveyed to upstream arterioles, remote from the area of activation, to increase flow efficiently [128]. Vascular mapping and fMRI demonstrated that vascular responses are first seen in the deep cortical lamina during somatosensory activation, and then, more superficially, suggesting a retrograde propagation of the vascular response [132]. A possible scenario for the transmission and coordination of the vascular response is described [128] as follows: the activation-induced increase in extracellular potassium triggers hyperpolarization of capillary endothelial cells and pericytes [133]. The hyperpolarization propagates upstream and reaches smooth muscle cells in penetrating arterioles producing relaxation [128, 130]. Simultaneously, metabolic modifications (reduced viscosity, increased deformability of blood cells) on the endothelium of feeding arterioles increment the smooth muscle cell relaxation (the so-called flowmediated vasodilation). In upstream pial arterioles, remote from the activation site, there is vasodilation, by propagation from arteriole downstream and acting as a local flow-mediated and myogenic response. For all the conditions mentioned above, SVD is defective in neurovascular coupling, even for endothelial and pericytes failure.

\section{Homocysteine and brain}

Hcy is a sulfur-containing non-protein toxic intermediary amino acid related to methionine metabolism [134], either degraded via the remethylation pathway or converted, via the transsulfuration pathway, into cysteine. The methionine synthesis is anticipated by the reduction of 5,10-methylenetetrahydrofolate to 5methyltetrahydrofolate (5-methylTHF) catalyzed by the flavin-containing methylenetetrahydrofolate reductase [135].

Homocysteine (Hcy) is related to the production of 5,10-methylenetetrahydrofolate, a fundamental step for the synthesis of thymidylate, purines, and methionine, employing vitamin B12 and folate as cofactors [136, 137,138, 139]. Methionine adenosyltransferase (MAT) catalyzes S-adenosylmethionine (AdoMet) in a reaction involving methionine and ATP [140, 141]. Every reaction made by methyltransferases produces Sadenosylhomocysteine (AdoHcy), which is a potent inhibitor of most of them [142, 143]. An AdoHcy hydrolase (SAHH) acts on AdoHcy, producing adenosine and homocysteine, and they need to be metabolized or transported out of the cell to prevent their accumulation [144]. This hydrolysis is a reversible reaction that favors S-Adenosyl-L-homocysteine $(\mathrm{SAH})$ synthesis. The S-Adenosyl-Methionine = AdoMet (SAM) to SAH ratio defines the cell's methylation potential [145]. If homocysteine is allowed to accumulate 
in normal conditions, it will be rapidly metabolized to SAH, which competes with SAM for the active site on the methyltransferase system [146, 147, 148, 149].

Homocysteine is also methylated in the entire body, but not in the brain, by betaine [150,151]. Homocysteine remethylation is catalyzed by the methionine synthase (MTR) enzyme, which requires vitamin B12 (Cbl) as a coenzyme [152, 153]. During the transsulfuration pathway, homocysteine is irreversibly degraded to cysteine. Cysteine is a precursor of glutathione, the most vital endogenous anti-oxidant [154]. In most tissues, homocysteine is either remethylated or exported out of the cell. Moreover, the methylation reactions are strongly necessary for the brain for the fact that SAM is the sole donor in numerous methylation reactions involving proteins, phospholipids, and biogenic amines [155], and for the packaging of many phospholipids [156].

Normal levels of Homocysteine (Hcy) range between 5-and 15 micromol/L, and in physiological conditions, plasma total (t) Hcy levels are $<15 \mathrm{micromol} / \mathrm{L}$, as reported by the majority of investigations. Less frequently, a threshold of $13 \mathrm{micromol} / \mathrm{L}$ has been reported, depending on the method of detection employed. Hyperhomocysteinemia (HHcy) is typically defined as levels $>15 \mathrm{~mol} / \mathrm{L}$ in reported studies; levels between 15-30 are considered moderate HHcy; levels at 30-100 micromol/L are considered severe HHCy; levels above $100 \mathrm{micromol} / \mathrm{L}$ are considered fatal HHcy [156].

The physiologic levels of Hcy in a healthy population are determined primarily by the dietary intakes of methionine [157], folate [158], and vitamin B12 [159]. Recent studies are generally confident with the fact that lifestyle conditions, such as smoking, alcohol consumption, and physical inactivity, may help the elevation of Hcy [160,161]. Aging is considered a strong determinant for homocysteine increase [162]. HHcy-induced oxidative stress, endothelium dysfunction, inflammation, smooth muscle cell proliferation, and endoplasmic reticulum stress have been considered to play an essential role in the pathogenesis of several diseases including atherosclerosis. Different epidemiological researches propose that increased homocysteine level is an independent risk factor for vascular diseases, including stroke and neurodegenerative disorders.

The clinical role of Hcy, and especially of its accumulation, is frequently controversial in standard clinical practice [163]. It seems quite evident that Hcy is not relevant, per se, at the moment, rather than its accumulation.

The best and undoubted cases are the ones determined by a genetic deficiency of Cystathionine - Synthase (CBS) and to other genetic alterations of remethylation and trans-sulfuration pathways, which induced severe HHCY (total Hcy $>50$ microM) or homocystinuria. Severe HHCY $(>100$ microM) in children with a CBS defect correlates with a 10-fold increase in concentrations of Hcy in cerebrospinal fluid (CSF) [164]. This genetic defect limits purines and thymidine synthesis due to a severe alteration/ inhibition of the transmethylation pathway. The final result is a severe delay or almost an abolition of the neural tube closure [165]. It has been demonstrated in animal models that Hcy could be intrinsically toxic, compromising the bloodbrain barrier [166]; the same mechanism has been postulated for human beings [167, 168].

The most crucial aspect of HHCy is the constant tendency to decrease the cell's methylation potential, interfering with the SAM/SAH ratio [169]. Therefore, HHcy promotes a generalized DNA hypomethylation, together with

the transcription of cyclin A in endothelial cells; opposite results induced by HHcy are the up-regulation of the p66shc expression, promoting oxidative stress [145, 169].

Homocysteine, therefore, could contribute SVD pathology with four mechanisms: promoting neurodegeneration, favoring neuro-inflammation, damaging endothelium, and finally activating oxidative stress. Nevertheless, there are not many studies directly concerning HCy or HHCy and SVD [162, 170, 171, $172,173,174]$.

Our review is an attempt to review the four principal mechanisms of HHcy induced damage with a focus on SVD.

\section{Homocysteine and Neurodegeneration}

Many clinical works try to focus on the possible direct consequences of Hcy inside neurodegenerative disorders: it is well-accepted that Hcy increases in CSF with aging, for not precise reasons. It has been demonstrated that there is a favorable condition, mediated by HHcy, of Abeta1-40 deposition in the brain of AD patients [175], mediated by an endoplasmic protein-HCY related (HERP), which potentiates the csecretase enzyme activity, and a direct potentiation of the intra- and extracellular accumulation of Abeta42 
$[176,177,178,179]$. Moreover, it is accepted that DNA hypomethylation mediated by HHcy up-regulate the presenilin genes, in particular, presenilin 1 (PS1), which promotes the amyloid precursor (APP) synthesis $[180,181]$. Besides, covalent protein modification by the metabolite of Hcy, Hcy thiolactone (HTL) ( see afterward), has now been shown to be another cause of cellular Hcy toxicity. This mechanism, termed as "protein N-homocysteinylation," is known to result in protein denaturation, enzyme inactivation, and even amyloid formation, and favor its oligomer depositions [182]. The role of protein N-homocysteinylation and the resulting consequences are an imbalanced mechanism, which lies in between inflammation and neurodegeneration. It is probably a mixer-result between potentiating misfolded protein accumulation and consequent neuronal death by starvation or hyper-activating inflammation.

Hcy is indirectly bound to the tau protein, too. Tau protein has many functions, mainly being the principal actor of the microtubules' assembly, and therefore, being the principal responsibility of the axonal nutrients transport. Tau protein needs a dephosphorylating system, regulated by protein phosphatase methyltransferase 1 and 2A (PPM1, PP2A), whose methylation is SAM-dependent [183, 184, 185, 186, 187]. Hyperphosphorylated tau (induced by the reduced methylation capacity by HHcy, or to an increased SAH) is an invalid protein, which inhibits the microtubules' congregation, whose precipitation determines the deposition of the neurofibrillary tangles, and the neuronal death by starvation [188, 189, 190]. The hyperphosphorylation of tau does not occur only in neurodegenerative conditions; the induced depletion of folic acid in neuroblastoma cultured cells, causing HHCY condition, produced an increase of P-TAU by $66 \%$ [191].

Moreover, HHCy has direct toxic effects when it is artificially induced inside brain models either by pressure ejection or ionophoresis [192]. Hcy acts as an agonist of the endogenous glutamate NMDA receptors [193, 194, 196, 196]. The Hcy-NMDA binding effect largely depends on glycine medium concentration; when glycine is in average concentration, Hcy acts as a partial antagonist of the NMDA receptors [155, 193]. When glycine medium concentration upraises, i.e., in brain ischemia, or functional arterial functional spastic condition, such as protracted migraine crisis, even low concentration of Hcy could become dangerous, acting as an agonist on NMDA [197, 198], enhancing overwhelming calcium influx currents [198]. It has also been hypothesized that Hcy can compete with GABA and directly activates group I metabotropic glutamate receptors, favoring substantial calcium influx [197]. HHcy can determine an extracellular signal-regulated kinase in the hippocampus, effect blocked by three types of glutamate receptor antagonists (NMDA, nonNMDA, and metabotropic receptors) $[155,199]$. By activating ionotropic and metabotropic receptors, HCY indirectly increases intracellular calcium level and activates several kinases [155, 199].

It has also been evidenced that HHcy leads to a severe reduction of dopamine turnover in the striatum, and that probably occurs due to a high affinity for Hcy in the third loop of the D2 receptor, and therefore Hcy exerts an allosteric antagonist activity of D2 receptors [200, 201].

Concerning SVD, HHcy has two significant implications: it has been found that HHcy increases Abeta (1-40) toxicity on the smooth muscle cells of small arteries in the brain, and that appears more evident in the cerebral amyloid angiopathy (CAA), which is frequently involved in SVD [202]. Nevertheless, it is also clear that Hcy induces the m-TNA production of the C-reactive protein (CRP), augmenting, therefore, the NR1 subunit of NMDA receptor expression. This way, HHCy, by CRP hyper-production, enhanced continuously by a combined

NMDA-ROS-erk1/2/p38-nfKBeta signal pathway [203] mediates a pro-inflammatory cascade inside the smooth cells of small arteries. All along with, it seems relatively easy to think that HHcy can promote atherosclerotic process, but also a substantial impedance of smooth muscle activity. Therefore, small arteries fail their precarious autoregulatory response, extend their diminishment of perfusion capabilities, and promote white matter alterations, accelerating the entire cascade of SVD events [204].

\section{Homocysteine and neuroinflammation}

It is challenging to talk about the relationship between neuroinflammation and HHcy and leave the crucial point of concomitant reduced anti-oxidative properties. It is well known that HHcy induces and accelerate the disruption of the redox system in vascular and neuronal cells [205], and these are the two processes that induce the lipid peroxidation sequel of events [206, 207]. Even though, HHcy has been directly claimed on the general principle of inducing inflammation, per se. It has been demonstrated that in severe inflammatory status, i.e., sepsis, comatose states, multiple traumatic lesions, there is a constant tendency of HHcy, not 
related to vitamin B12 and folate poorness [208]; by the way, it has been implemented all these cases with generous doses of vitamin B12 and with folate. The implementation does not reduce HHcy and does not affect inflammatory markers, such as Il-6, TNFalpha, CRP, etc.; on the contrary, folate integration only reduces neopterin, suggesting a possible modulating role of folic acid in

the inflammatory cascade [208]. In different clinical scenarios, the systemic inflammatory response is constantly related to a poor clinical outcome [209], which is probably mediated by sustained HHCy activation of the macrophage-system cascade, with a consequent increment of ROS production, and therefore a potentiation of the oxidative stress. The virtual loop is an overwhelming, auto-potentiated system. Animal models definitively show that HHcy induced a constant increase of TNF-alpha and Il-1 beta, together with a decrease of $\mathrm{H} 2 \mathrm{~S}$ and cystathionine-gamma-lyase in macrophages. HHcy upregulates methyltransferase expression and induces hypermethylation in many different macrophage promotor regions [210, 211, 212]. Cultured macrophages exposed to HHcy show a so-called memory response, probably derived by an epigenetic mutation, which strongly influences the expression of inflammatoryinducers genes and endothelium altered-response inflammation [210]. There is also an in-vitro demonstration of altered transcriptional fibroblast growth factor 2 induced by HHcy exposure [213]. HHcy possesses a direct effect on the endothelium, and, even if without a note mechanism, it releases inflammatory cytokines from vascular endothelial cells, such as IL-6, IL-8, and TNF-alpha [214, 215, 216]. There is an interesting response in endothelium to TNF-alpha, high production of cathepsins [217]. The serum level of cathepsins are associated with cardio- and cerebrovascular diseases [218], especially cathepsin $\mathrm{V}[219,220]$. Cathepsins are lysosomal cysteine proteases and belong to the papain family of proteases that comprises 11 members, while endothelial cells mainly express cathepsin K, B, S, L, and V [221, 222]. Cathepsins are involved in vascular remodeling and inflammation [223]. One of the unresolved problems is that cathepsin $\mathrm{V}$ is mainly expressed outside of the nucleus. Therefore, to determine its effects on remodeling and the regeneration of affected endothelium, it should exist a nuclear translocation mechanism capable of transferring the cathepsin $\mathrm{V}$ signal into the nucleus. A very recent experimental data sequence shows that a high methionine diet-induced HHcy mouse model was used to assess cathepsin V expression and vascular inflammation [224]. The authors firstly demonstrate that Cathepsin L (human cathepsin V homologous) was increased in the thoracic aorta endothelial cells of hyperhomocysteinemic mice [224]. Moreover, high concentrations of N-[(1,1-dimethyl ethoxy)carbonyl]-L-tryptophan-2-[[[2-[(2- ethyl phenyl)amino]-2oxoethyl]thio]carbonyl]hydrazide (SID) suppressed the activity of cathepsin V. It reversed the up-regulation of inflammatory cytokines (IL-6, IL-8, and TNF- $\alpha$ ), adhesion and chemotaxis of leukocytes and vascular inflammation induced by L-homocysteine in vivo and in vitro [224]. Cathepsin S enhances the VEGF/ERK1/2 signaling pathway [225]. Moreover, cathepsin V upregulated the expression of IL- 6 and TNF- $\alpha$, but not that of IL-8, via the ERK1/2/STAT1 pathway [224]. ERK1 and ERK2 are related to protein-serine/threonine kinases that participate in the Ras-Raf-MEK-ERK signal transduction cascade. This cascade participates in regulating a large variety of processes, including cell adhesion, cell cycle progression, cell migration, cell survival, differentiation, metabolism, proliferation, and transcription. In physiological conditions, ERK1/2 is unphosphorylated in the cytosol but is translocated to the nucleus upon phosphorylation. ERK1/2 phosphorylation is maintained by a balance between MAP kinase and ERK kinase (MEK1/2) activation and is negatively controlled by compounds such as the Dual-specificity phosphatases (DUSPs). DUSPs inactivate ERK1/2 by dephosphorylating both the phosphoserine/threonine and phosphotyrosine residues [224]. The authors demonstrate that increased expression of cathepsin $\mathrm{V}$ promotes the phosphorylation and subsequent nuclear translocation of ERK1/2, possibly through degradation of DUSP6 and DUSP7. Phospho-ERK1/2 can phosphorylate and activate its downstream signaling molecule (such as transcription factor STAT1) in the nucleus, and phospho-STAT1 will promote the transcription of target genes (such as IL-6 and TNF- $\alpha$ ) [224, 25]. Genome-wide analysis revealed that the hypomethylation (predisposed by HHcy status) of chromosomal DNA predominates in atherosclerotic plaques [226], where inflammation status predominates. Moreover, it has been described a B-activation cascade of events, induced by HHcy, probably induced by an up-regulation of pyruvate kinase muscle isozyme 2 (PKM-2) in B cells, which mainly promotes the inflammatory basis of atherosclerosis cascade, demonstrated in vivo and in vitro and which is primarily inhibited by shikonin [227].

There is a possible link between the excitotoxic effect of Hcy and the pro-inflammatory role of 
Hcy: the NMDA receptors are found not only in neurons (see above in the text), but also on neutrophils and macrophages. The activation of these receptors, as well as in the cerebral context, arises the cytoplasmatic calcium influx, and activates a pro-inflammatory cascade, with an accumulation of ROS species [228]. In fact, in the Rheumatoid Arthritis, as an example, [229] HHcy is two times more frequent than in the general population and HHcy contributes to the oxidative stress, and, indirectly, by the excess of ROS released, it induces an up-regulation of the Nuclear Factor Kappa B, considered as one of "the master regulator of the expression of inflammatory genes" [230].

In this context, a recent series of studies put in evidence that HHcy might relate to an overproduction of other products, such as asymmetric dimethylarginine (ADMA), that is an endogenous inhibitor of endogenous nitric oxide synthase (eNOS), the enzyme catalyzing the formation of nitric oxide

(NO) from arginine. This endogenous inhibitor of endothelial nitric oxide synthase (eNOS) competes with the natural substrate, L-arginine, limiting the formation of NO, similarly to Hcy.

Plasma levels of ADMA have been reported to be positively correlated with plasma homocysteine levels [231, 232, 233, 234]. Protein arginine N-methyltransferases (PRMTs) 1 and 2 are involved in the methylation of protein arginine residues. PRMTs utilize SAM as a methyl donor and generate SAH (and ultimately Hcy) as a byproduct [222]. Hcy enhances the activity of PRMT 1 and also increases the proteolysis of proteins with methylated arginine residues. The major pathway for ADMA's metabolism is the formation of citrulline and methylamine mediated by dimethylarginine dimethylaminohydrolase (DDAH) [234, 235]. Similarly, Hcy can influence the activity of DDAH, which would prevent the metabolism of ADMA and thus bring down the levels of NO. Also, Hcy may elevate ADMA levels by inducing ER stress and cell death, leading to increased proteolysis of proteins that contain methylarginine residues [101, 102]. The likelihood of HHcy enhancing PRMT activity is controversial since it results in high levels of SAH [101]. It remains possible, however, that the inhibitory effect of high levels of SAH in HHcy might compensate for the increased expression of PRMT $1[234,235,236,237,238]$.

HHcy upregulates the matrix metalloproteinases-9 (MMP-9) expression, a pro-inflammatory proteinase that is over-expressed when there is either in clinical or in the experimental condition rupture of the atherosclerotic plaque [234, 239]. Circulating apoptotic endothelial cells have been observed in severe HHcy patients' bloodstream, suggesting that endothelial dysfunction. A pathologically relevant level of homocysteine can induce apoptosis in cultured endothelial cells mediated by endoplasmic reticulum (ER) stress and unfolded protein response (UPR) [240]. It is widely known that any accumulation of unfolded and aggregated proteins results in ER stress, causing a cascade of events, the UPR [241]. It is well-accepted that UPR upregulates the ER, mediating an increased production of chaperons, and downregulating the ER protein load, via a control on transcription and translation process [241, 242]. Whenever there is a persistent hyper-activation of ER protein folding capacity, UPR cannot resolves it, and damaged cells should be removed. HHcy is an elicitor of ER stress condition [243]; therefore, an HHcy condition leads to hyperactivation of UPR responses, and when the system is under stress, in a dose-dependent relationship, promoting apoptotic responses. The first is the activation of CHOP/ GADD153 (growth arrest- and DNAdamage inducible gene 153). The second is the activation of TDAG51 (T-cell death-associated gene 51) and the initiation of detachment-mediated apoptosis [243, 244, 245]. Over-expression of the latter in endothelial cells has been shown to cause cell rounding up, an extension of cell pseudopods, dramatic loss of cell adhesion, and caspase-dependent cell death [243, 245]. Moreover, other facts occur in HHcy condition. When the SAH/SAM is high, there is a low methylation condition. That is the main determinant of the fact that the enzyme that links methionine to its conjugate t-RNA (the methionyl-tRNA synthase (MetRS)) attacks homocysteine instead of methionine, causing the thiol group and the carboxyl group of homocysteine to join with each other by thioester linkage [243, 245]. That results in the generation of cyclic derivative homocysteine thiolactone [243, 246, 247]. The thioester group of thiolactone actively reacts with any lysine residues in proteins to form amide bonds in a process known as N-homocysteinylation [243, 245, 248]. Naturally, the rate of N-homocysteinylation proportionally increases with the number of lysine residues [243, 247, 249]. N-homocysteinylated proteins tend to aggregate: the most interesting aspect is that multiple lysine-rich proteins include fibrinogen [247, 248], high-density lipoprotein [248], lysine oxidase [246], and cytochrome c [249], potential and virtual target of the N-homocysteinylation [243]. Homocysteine thiolactone induces apoptosis directly in endothelial cell cultures in vitro and in vivo models [243]. HHcy due to N- 
homocysteinylation also induces a prothrombotic condition for its effect on fibrinogen [247, 248, 250, 251], and enhanced platelet activation, enhanced coagulation [252], and attenuated fibrinolysis [253, 254]. Moreover, enhanced expression of the receptors for advanced glycation end products, vascular cell adhesion molecule-1, tissue factor, and MMP-9 was found in a mouse model with methionine-induced hyperhomocysteinemia [243, 255]. However, contradicting results have indicated that the inflammatory response induced by homocysteine occurred in vascular smooth muscle cells, and not at the endothelium, which could be a target of HHcy by redox impairment, by stimulating CRP production, which is mediated through the NMDAr-ROS-ERK1/2/ p38-NF-kB signal pathway [243, 256].

HHcy-induced toxicity is thought to be also mediated by an indirect effect on the global "Cellular protein quality control" (PQC). PQC is essential for maintaining proteome integrity and cell viability, and its failure contributes to the development of multiple diseases [257]. Chaperones, UPR, ubiquitin-proteasome system (UPS), and autophagy are analogous strategies of PQC that maintain cellular proteome integrity. Recently, multiple studies reported that HHcy responsible for the perturbation of PQC by reducing chaperone levels, activating UPR, and impairing autophagy [257, 258, 259]. Besides, HHcy also induces cytotoxicity, inflammation, protein aggregation, and apoptosis. It has been shown that some of the factors, including altered sirtuin1/heat shock factor 1/heat shock protein axis (SIRT1-HSF1 axis) and irreversible homocysteinylation of proteins, are responsible for folate and/or B12 deficiency or HHcy-induced impairment of PQC [260].

It has been demonstrated that HHcy treatment enhanced brain injury, induced activation of microglia, and triggered the expression of pro-inflammatory cytokines in the om mice models [261]. This is the first study [261] to provide evidence that changes in the signal transducer and activator of transcription 3 (STAT3), a member of the STAT protein family of transcription factors activities located in microglia. The STAT3 has been extensively described as a central signaling molecule that controls cellular adaption in response to environmental stimuli or stress. Several groups have shown that the STAT3 is activated in vitro and in vivo experimental models of stroke. Subsequently activated - STAT3 promotes numerous genes responsible for neural injury and repair $[262,263]$. Data on recovery progressions STAT mediated are quite controversial [264], and most of the newest data converge towards their implication in a poorer stroke outcome [265]. Nevertheless, what is almost evident is the role of STAT3 as a regulator of inflammatory gene expression in microglial pro-inflammatory reactivity to various stimuli [266]. In the model reported [264], HHCy treatment activated microglial cells, with consequent enlargement of the infarction volume, with a subsequent increment of IL-1Beta, TNF-alpha, and IL-6, aggravating the brain damage [267, 268].

\section{Homocysteine and oxidative stress}

Mechanisms of action of Hcy are an ongoing development, but the most substantial evidence derives from its antioxidant effect, the primary biochemical mechanism responsible for hHcy-related pathogenesis [166, $248,269,270]$. Oxidative stress is defined as a severe imbalance between the production of reactive species and antioxidant defenses and can result from diminished levels of antioxidant and/or increased production of reactive species [206, 271]. Redox reactions are fundamental in endothelium regulation, platelet aggregation, and atherosclerosis induction. Oxidative stress is generated during oxidation of the free thiol group of Hcy when Hcy binds via a disulfide bridge with plasma proteins - mainly albumin - or with other low-molecular plasma thiols, or with a second Hcy molecule. Accumulation of oxidized biomolecules, such as superoxide anion (O2-) and hydrogen peroxide ( $\mathrm{H} 2 \mathrm{O} 2)$, mainly during its auto-oxidation, alters the biological functions of many cellular pathways [206]. Increasing evidence suggests that elevated plasma Hcy affects the body's oxidant-antioxidant balance following endothelial injury [272]. Five mechanisms have been proposed for Hcy-induced oxidative stress [206]. They include

1. inhibition of cellular antioxidant enzymes,

2. Hcy auto-oxidation,

3. nitric oxide synthase (NOS)-dependent generation of superoxide anion via uncoupling of endothelial NOS (eNOS),

4. disruption of extracellular superoxide dismutase from endothelial surfaces, and

5. activation of NADPH oxidases [206]. 
ROS and oxidative stress promote nitrotyrosine, an indicator of NO and superoxide radical reaction, resulting in the formation of strong oxidant peroxynitrite [206]. Peroxynitrite leads to tyrosine nitration, which induces significant cellular dysfunctions [273]

$\mathrm{HHCY}$ also increases $\mathrm{NAD}(\mathrm{P}) \mathrm{H}$ oxidase activity, which in turn triggers microglia activation and stimulates the secretion of pro-inflammatory molecules such as arachidonic acid and cytokines [274, 275].

Homocysteine also directly inhibits antioxidants' activity, thereby disrupting SOD, activating NADPH oxidases (NOXs), and subsequently producing superoxide anion, causing an accumulation of ROS. The generated ROS further activates the transcriptional activity of NF- $\mathrm{KB}$, which results in the expression of proinflammatory genes and vascular inflammation $[3,276]$. HHcy plays an essential role in the pathogenicity of cardiovascular diseases. In atherosclerosis (AS) (a progressive disease of multifactorial origin, which occurs in response to endothelial injury) has been shown that HHcy is the primary cause of endothelial dysfunction due to oxidative stress and DNA methylation. Several mechanisms have been indagated to understand the role of HHcy. Recent work has demonstrated that HHcy injured the endothelial through the effect of methylation and trans-sulfuration metabolism of lectin-like oxidized low-density lipoprotein receptor-1 (LOX-1) through toll-like receptor 4(TLR4)/nuclear factor (NF)-kB/DNA methyltransferase (DNMT)1. Following an injury to the endothelial cells, lipids accumulate in the subendothelial layer to promote atherosclerosis formation [277]. The endothelial damage is mediated by one of the precursors, hydrogen sulfide (H2S), formed during the transsulfuration process [162, 278]. The disruption of the redox system in vascular and neuronal cells induces and accelerates the lipid peroxidation sequel of events [205.]. The vascular endothelium is a single layer of dynamic cells that produces vasoactive substances to maintain the vascular tone and regulate blood flow to the tissues through a variety of stimuli. Among these, this effect was attributed to a substance(s), subsequently identified as nitric oxide (NO) [279].

In animal models, HHcy, increasing oxidative stress, induces the upregulation expression of proteins that promote blood coagulation, exacerbates traumatic brain injury-associated blood-brain barrier dysfunction, and promotes the infiltration of inflammatory cells into the cortex [206]. An increase of brain injury-induced lesion size and aggravated anxiety-like behavior has been observed, suggesting that moderate HHcy exacerbates traumatic brain injury outcomes and that Hcy catabolic dysregulation may be a significant biological variable that could contribute to traumatic brain injury pathophysiology heterogeneity [280]. Endothelial dysfunction also results from a disruption in the cellular integrity, leading to impaired endothelium-dependent relaxation mainly due to a reduction in the nitric oxide (NO) bioavailability. NO is produced from its precursor L-arginine by endothelial nitric oxide synthase (eNOS). Under physiological conditions, following production, $\mathrm{NO}$ diffuses across the endothelial cell membrane into the vascular smooth muscle cells to activate guanylate cyclase, leading to subsequent cyclic guanosine-30,5monophosphate (cGMP)-mediated vasodilation. Several molecules, such as acetylcholine, bradykinin, serotonin, and substance $\mathrm{P}$, can induce eNOS. HHcy-induced ROS production decreases NO production and bioavailability, triggering increased redox signaling. Impaired NO production during HHcy can also occur due to inhibition of Dimethylarginine dimethylaminohydrolase (DDAH), causing Asymmetric dimethylarginine (ADMA) accumulation [281, 282, 283,284].

Another critical stimulus is the shear stress exerted by the flowing blood, which can cause ion channel activation for a rapid response or through a phosphorylation process to induce the sustained release of NO to maintain vasodilation [285].

Hcy has been linked to an increment of ROS and deactivation of nitric oxide and the well-known inflammation cascade [206, 207]. Oxidative stress as a result of ROS accumulation is the primary mechanism that mediates homocysteine-induced vascular injury [286]; finally, a possible link between Hcy and lowered melatonin production has been reported [287], and it has been demonstrated that melatonin scavenges free radicals [288] and counteracts Hcy by a direct antioxidant effect and by apoptosis modulation [289, 290]. Recently, a well-conducted study [291] conducted on neuroblastoma cells incubated with Hcy determined some different and time- and concentration-dependent results. The highest concentration of Hcy determines cellular death after five days of incubation. Forty microM Hcy conducted to a $35 \%$ of cell death after five days of incubation. Quite impressive, cell exposure to Hcy for three days does not induce any change in Reactive Oxygen Species (ROS); exposure to Hcy for five days elevated to a 4.4 fold increase ROS production. A five days incubation with Hcy induced a 2-fold increase of Bax mRNA and 14-fold of Bcl-2 mRNA. A 
three-days incubation with Hcy induces an increase of 2-fold for cyclin D1 mRNA, 6-fold for cyclin E1 mRNA, and 5-fold for cyclin A1 mRNA [3]. Unexpectedly, all the levels turn back to a normal range after five days of incubation. This study points out that there is a general upregulation of p21 and p-16 after five days of Hcy incubation, inducing a reduction of 35\% of pRB, checkpoint regulators of G1 cell-cycle phase. This work suggests potential genotoxic stress, time-exposure, and Hcy concentration-related. In response to the higher Hcy level, endothelial cells produce NO to induce the formation of S-nitrose-Hcy, which acts as a protector of endothelium; however, with chronic exposure to Hcy, NO levels diminish [182.] and this fact, associated to the high levels of Hcy, promotes endothelial damage. The first by stimulation of muscle cells, vasoconstriction, and promoting inflammatory response, testified by an increase of c-reactive protein and cysteinyl leukotrienes, was associated with an incremental increase in HMG-CoA reductase activity [292]. The activities of methionine synthase that mediate the clearance of Hcy are linked to the redox potential of the cells [293, 294], with an observed efficacy in the oxidative stress process; in this situation, more Hcy is converted into cysteine and glutathione. A disruption of the CBS causes altered redox homeostasis, and through a reduction of the cysteine and glutathione, it causes an alteration of the oxidative repairing process [295].

On the other side, different studies demonstrate that the antioxidants, such as N-acetyl cysteine, vitamin E, or C might reduce the potential pro-inflammatory response of Hcy in animal models [296,297]. Different in vivo reports recognized that the Th1-activity induced the Hcy inflammation response [298], and it appears that HHcy can be detected in chronic inflammatory conditions, even if vitamin B12 and folate are in range. A recent study promoted oxidative injury and apoptotic cell death in human umbilical vein endothelial cells by Hcy [299]. High level of Hcy promotes ROS accumulation in human umbilical vein endothelial cells through Hcy auto-oxidation that causes oxidative stress [286]. Hyperhomocysteinemia damages endothelial cell function, increases oxidative stress and enhances apoptosis via the intrinsic apoptotic pathway [300]. Indeed, increased levels of ROS and lipid peroxidation are the markers of oxidative damage. ROS and malondialdehyde generation are concurrent with Hcy-induced apoptosis [301]. ROS generation is significantly decreased by treating the cells with melatonin, vitamin E, or both.

Then, homocysteinylation is another mechanism of damage, strongly related to the three pathogenic mechanisms (neurodegenerative, neuroinflammatory, and oxidative) by which Hcy does its damages. Two homocysteinylation systems have been detected: S-homocysteinylation and N-homocysteinylation, both considered posttranslational protein modifications [206]. S-homocysteinylation occurs when Hcy reacts, by its free thiol group, with another free thiol derived from a cysteine residue in a protein molecule. These changes can alter the thiol-dependent redox status of functional proteins [247]. N-homocysteinylation occurs after acylation of the free amino (e.g., lysine) groups of different proteins to form adducts under physiological conditions, and its degree depends on the Hcy levels [247]. It appears that the conversion of Hcy to Hcy-thiolactone followed by protein N-homocysteinylation largely contributes to manifestations of Hcy toxicity [246]. Naturally, the rate of N-homocysteinylation proportionally increases with the number of lysine residues [243, 247, 249]. N-homocysteinylated proteins tend to aggregate: the most exciting aspect is that multiple lysine-rich proteins include, as above reported, fibrinogen [247, 248], high-density lipoprotein [248], lysine oxidase [246] and cytochrome c [249], potential and virtual target of the N-homocysteinylation [243]. Homocysteine thiolactone induces apoptosis directly in endothelial cell cultures in vitro and in vivo models [243]. Moreover, enhanced expression of the receptor for advanced glycation end products, vascular cell adhesion molecule-1, tissue factor, and MMP-9 was found in a mouse model with methionine-induced hyperhomocysteinemia [243, 255].

\section{CONCLUSIONS}

To write on HHcy and SVD is a novelty, and even though some clinical studies have been done [162, 170, 171, 172, 173, 174], mechanisms, processes, and reactions have developed continuously and established as potential damage mechanisms. It is an extraordinary- ongoing cultural development and conquest. Hard to say, it is only an academic status at the moment. Firstly, because we, as many others, continue to describe HHcy role dividing it, for academic meticulosity into different ways of happening; the truest possibility is that inflammation, oxidative damages, misfolding, and neurodegeneration happen all together, in a very dynamic (and not at all static) photogram sequence. 
Secondly, because biochemical and histological pieces of knowledge are very distant and their application far from a clinical application.

Thirdly, there is no adequate number of studies that interface, at the moment, lab to a hospital ward, and try to detect a specific point of sharing the vision in between lab developments and clinical outcomes (we are still debating on how SVD happens to become sVAD).

These obscure points will or should be the future targets of prospective studies to simplify the basic science knowledge and finally be keen to apply in clinical practice.

References

1. Pantoni L and Gorelick P, Cerebral Small Vessel Disease, Cambridge University Press, Cambridge, UK, 1st edition, 2014.

2. $\mathrm{Xu} \mathrm{WH.} \mathrm{Large} \mathrm{artery:} \mathrm{an} \mathrm{important} \mathrm{target} \mathrm{for} \mathrm{cerebral} \mathrm{small} \mathrm{vessel} \mathrm{diseases.} \mathrm{Ann.} \mathrm{Transl.Med.} 2014$ 2:78. doi:10.3978/j.issn.2305-5839.2014.08.10.

3. Moretti R, Caruso P. The Controversial Role of Homocysteine in Neurology: From Labs to Clinical Practice. Int J Mol Sci. 2019;20(1):231. Published 2019 Jan 8. doi:10.3390/ijms20010231.

4. Vinciguerra, L.; Lanza, G.; Puglisi, V.; Fisicaro, F.; Pennisi, M.; Bella, R.; Cantone, M. Update on the Neurobiology of Vascular Cognitive Impairment: From Lab to Clinic. Int. J. Mol. Sci. 2020, 21, 2977.

5. Pantoni L. Cerebral small vessel disease: from pathogenesis and clinical characteristics to therapeutic challenges. Lancet Neurol 2010;9:689-701.

6. Zhang ET, Inman $\mathrm{CB}$, Weller RO. Interrelationships of the pia mater and the perivascular (Wirchov-Robin) spaces in the human cerebrum. J. Anatom. 1990; 170: 111-123.

7. Iadecola C. The neurovascular Unit coming of age: a journey through neurovascular coupling in health and disease. Neuron 2017: 27; 96(1):17-42. Doi:10.1016/jneuron.2017.07030.

8. Caruso P, Signori R, Moretti R. Small vessel disease to subcortical dementia: A dynamic model, which interfaces aging, cholinergic dysregulation and the neurovascular unit. Vascular Health and Risk Management. 2019; 15: 259-281.

9. Sweeney MD, Sagare AP, Zlokovic BV. Blood-brain barrier breakdown in Alzheimer disease and other neurodegenerative disorders. Nat Rev Neurol 2018. volume 14, pages133-150.

10. Abbott NJ, Pizzo ME, Preston JE, Janigro D, Thorne RG. The role of brain barriers in fluid movement in the CNS: is there a 'glymphatic' system? Acta Neuropathol 2018;135(3): 387-407.

11. Huijts M, Duits A, Staals J, et al. Basal ganglia enlarged perivascular spaces are linked to cognitive function in patients with cerebral small vessel disease. Curr Neurovasc Res 2014;11:136-41.

12. Jiménez-Balado J, Riba-Llena I, Garde E, Valor M, Gutiérrez B, Pujadas F, Delgado P. Prevalence of hippocampal enlarged perivascular spaces in a sample of patients with hypertension and their relation with vascular risk factors and cognitive function. J Neurol Neurosurg Psychiatry 2018;0:1-6. doi:10.1136/jnnp-2017-316724.

13. Garcia JH, Lassen NA, Weiller C, Sperling B, Nakagawara J. Ischemic stroke and incomplete infarction. Stroke 1996, 27, 761-65.

14. Dalkara T, Alarcon-Martinez L. Cerebral micro-vascular signaling in health and disease. Brain Res.2015, Volume 1623, 14, Pages 3-17.

15. Giannakopoulos P, Gold G, Kowaru E, von Gunten A, Imhof A, Bouras C, et al. Assessing the cognitive impact of Alzheimer disease pathology and vascular burden in the aging brain: the Geneva experience. Acta Neuropathol. 2007, 113, 1-12.

16. Launer LJ, Hughes TM, White LR. Microinfarcts, brain atrophy, and cognitive function: the Honolulu Asia Aging Study Autopsy Study. Ann. Neurol. 2011, 70, 774-780.

17. Munoz DG, Hastak SM, Harper B, et al. Pathologic correlates of increased signals of the centrum ovale on magnetic resonance imaging. Arch Neurol 1993, 50, 492-497. 
18. Mirski MA. Pharmacology of blood pressure management during cerebral ischemia. American Academy of Neurology (AAN). Miami, 2005: 5PC-004:456-469.

19. Wallin A, Blennow K, Gottfries CG. Neurochemical abnormalities in vascular dementia. Dementia 1989, 1, 120-130.

20. Jani BI, Rajkumar C. Ageing and vascular ageing. Postgrad Med J. 2006, 82, 357-62.

21. De la Torre JC. Vascular basis of Alzheimer's pathogenesis. Ann N Y Acad Sci. 2002, 977, 196-215.

22. Mathias CJ, Kimber JR. Postural hypotension: causes, clinical features, investigation, and management. Annu. Rev. Med. 1999, 50, 317-36.

23. Roriz-Filho JS, Bernardes Silva Filho SR, Rosset I, Roriz-Cruz M. Postural blood pressure dysregulation and dementia: evidence for a vicious circle and implications for neurocardiovascular rehabilitation. In: Cardiac Rehabilitation. Novascience Publisher Inc. NY, USA. 2009; JT Halliday (Ed). Pp 1-37. ISBN: 987-1-60741-918-1.

24. Wardlaw JM, Smith EF, Biessels GJ, Cordonnier C, Fazekas F, Frayne R, et al. Neuroimaging standards for research into small vessel disease and its contribution to ageing and neurodegeneration. Lancet Neurol. 2013, 12, 822-832.

25. Black S, Gao F, Bilbao J. Understanding white matter disease: imaging-pathological correlations in vascular cognitive impairment. Stroke 2009;40:S48-52.

26. Tullberg M, Fletcher E, DeCarli C, Mungas D, Reed BR, Harvey DJ, et al. White matter lesions impair frontal lobe function regard- less of their location. Neurology 2004, 63, 246-253.

27. Gold G, Kovari E, Herrmann FR, Canuto A, Hof PR, Michel JP, et al. Cognitive consequences of thalamic, basal ganglia, and deep white matter lacunes in brain aging and dementia. Stroke 2005, 36, 1184-1188.

28. Salloway S. Subcortical vascular dementia: Binswanger's and CADASIL. American Academy of Neurology (AAN). Honolulu, 2003: 8AC.006-2, 1-29.

29. Pantoni L, Garcia JH, Gutierrez JA. Cerebral white matter is highly vulnerable to ischemia. Stroke 1996, 27, 1641-1647.

30. Schmidt R, Schmidt H, Haybaeck J, Loitfelder M, Weis S, Cavalieri M, et al. Heterogeneity in agerelated white matter changes. Acta Neuropathol 2011, 122, 171-185.

31. Hommet C, Mondon K, Constans T, Beaufils E, Desmidt T, Camus V, et al. Review of cerebral microangiopathy and Alzheimer's disease: relation between white matter hyperintensities and microbleeds. Dement Geriatr Cogn Disord 2011, 32, 367-378.

32. Bohnen NI, Muller MLTM, Kuwabara H, Ocnstantien GM, Studentski SA. Age-associated leukoaraiosis and cortical cholinergic deafferentation. Neurology 2009, 72, 1411-1416.

33. Román GC. Brain hypoperfusion: a critical factor in vascular dementia. Neurol. Res. 2004, 26, 454458.

34. Zhan SS, Beyreuther K, Schmitt HP. Synaptophysin immunoreactivity of the cortical neuropil in vascular dementia of Binswanger type compared with the dementia of Alzheimer type and nondemented controls. Dementia 1994, 5, 79-87.

35. Ahtiluoto S, Polvikoski T, Peltonen M, Solomon A, Tuomilehto J, Winblad B, et al. Diabetes, Alzheimer disease, and vascular dementia: a population-based neuropathologic study. Neurology 2010, 75, 1195-1202.

36. Englund EA, Person B. Correlations between histopathologic white matter changes and proton MR relaxation times in dementia. Alzheimer Dis. Assoc. Disord. 1987; 1, 156-70.

37. Román GC. Senile dementia of the Binswanger type: a vascular form of dementia in the elderly. JAMA 1987, 258, 1782-88.

38. Vinters HV, Ellis WG, Zarow C, et al. Neuropathological substrate of ischemic vascular dementia. J. Neuropathol. Exp. Neurol. 2000, 59, 931-45.

39. Moody DM, Brown WR, Challa VR, and Anderson RL. Periventricular venous collagenosis: association with leukoaraiosis. Radiology 1995 194, 469-476.doi:10.1148/radiology.194.2.7824728.

40. Van der Veen PH, Muller M, Vinken KL, et al. Longitudinal relationship between cerebral small vessel disease and cerebral blood flow. The second manifestations of arterial disease-magnetic resonance study. Stroke 2015, 46, 1233-1238. 
41. Gouw AA, van Der Flier WM, Fazekas F, et al. Progression of white matter hyperintensities and incidence of new lacunes over a 3-year period: the leukoaraiosis and disability study. Stroke 2008, 39, 1414-1420.

42. Schmidt R, Seiler S, Loitfelder M. Longitudinal change of small vessel disease related brain abnormalities. J. Cerebr, Blood Flow Metab. 2016, 36, 26-39.

43. Munoz-Maniega S, Chappell FM, Valdes-Henrandez ML, et al. Integrity of normal appearing white matter: influence of age, visible lesion burden and hypertension in patients with small-vessel disease. J. Cerebr. Blood Flow Metab. 2016, 37, 644-656 Doi: 10.1177/027168x16635657.

44. Smallwood A, Oulhaj A, Joachim C, Christie S, Sloan C, Smith AD, et al. Cerebral subcortical small vessel disease and its relation to cognition in elderly subjects: a pathological study in the Oxford Project to Investigate Memory and Ageing (OPTIMA) cohort. Neuropathol. Appl. Neurobiol. 2012, 38, 337-343.

45. Kramer JH, Reed BR, Mungas D, Weiner MW, Chui H. Executive dysfunction in subcortical ischaemic vascular disease. J. Neurol. Neurosurg. Psychiatr. 2002, 72, 217-220.

46. Burton E, Ballard C, Stephens S, Kenny RA, Kalaria R, Barber R, et al.Hyperintensities and frontosubcortical atrophy on MRI are substrates of mild cognitive deficits after stroke.Dement.Geriatr.Cogn.Disord.2003, 16, 113-118.

47. Cheng B, Golsari A, Fiehler J, Rosenkranz M, Gerloff C, Thomalla G. Dynamics of regional distribution of ischemic lesions in middle cerebral artery trunk occlusion relates to collateral circulation. J. Cereb. Blood Flow Metab. 2010, 31, 36-40. doi: 10.1038/jcbfm.2010.185.

48. Dijkhuizen RM, Knollema S, van der Worp HB, Ter Horst GJ, De Wildt DJ, Berkelbach van der Sprenkel JW, et al. Dynamics of cerebral tissue injury and perfusion after temporary hypoxiaischemia in the rat: evidence for region-specific sensitivity and delayed damage. Stroke 1998, 29, 695-704.

49. Garcia JH, Liu KF, Ye ZR, Gutierrez JA. Incomplete infarct and delayed neuronal death after transient middle cerebral artery occlusion in rats. Stroke 1997, 28, 2303-2309.

50. Konaka K, Miyashita K, Naritomi H. Changes in diffusion-weighted magnetic resonance imaging findings in the acute and subacute phases of anoxic encephalopathy. J. Stroke Cerebrovasc. Dis. 2007, $16,82-83$.

51. Ravens JR. Vascular changes in the human senile brain. Adv. Neurol. 1978, 20, 487-501

52. Klassen AC, Sung JH, Stadlan EM. Histological changes in cerebral arteries with increasing age. J. Neuropathol. Exp. Neurol. 1968, 27, 607-23.

53. Cummings JL. Frontal-subcortical circuits and human behavior. Arch. Neurol. 1993, 50, 873-80.

54. Mega MS, Cummings JL. Frontal-subcortical circuits and neuropsychiatric disorders. J. Neuropsychiatry Clin. Neurosci. 1994, 6, 358-70.

55. Kumar V, Cotran, RS, and Robbins SL Basic pathology. 2007. 8th Edn. Philadelphia, PA: Saunders, Moritz A, Oldt M. Arteriolar sclerosis in hypertensive and non-hypertensive individuals. Am J Pathol. 1937; 13: 679.

56. Lodder J, Bamford JM, Sandercock PA, et al. Are hypertension or cardiac embolism likely causes of lacunar infarction? Stroke 1990;21:375-81.

57. Gamble C. The pathogenesis of hyaline arteriosclerosis. Am J Pathol. 1986 Mar; 122(3): 410-420.

58. Pavelka M, Roth J. Hyaline Arteriolosclerosis. In: Functional Ultrastructure. Springer Verlag, Vienna. 2010. Pp 256-257.

59. Najjar SS, Scuteri A, Lakatta EG. Arterial aging: is it an immutable cardiovascular risk factor? Hypertension (2005) 46:454-62.

60. O'Rourke MF, Safar ME. Relationship between aortic stiffening and microvascular disease in brain and kidney: cause and logic of therapy. Hypertension (2005) 46:200-4.

61. Cervós-Navarro J, Matakas F, Roggendorf W, Christmann U. The morphology of spastic intracerebral arterioles. Neuropathol Appl Neurobiol (1978) 4:369-79.

62. Wakita H, Tomimoto H, akiguchi I, Kimura J. Glial activation and white matter changes in the rat brain induced by chronic cerebral hypoperfusion: an immunoistochemical study. Acta Neuropathol (1994) 87 (5): 484-492. 
63. Farkas E, Donka G, de Vous RAI, Mihaly A, Bari F, Luiten PGM. Experimental cerebral hypoeprfusion induces white matter injury and microglial activation in the rat brain. Acta Neuropathol. (2004) 108: 57-64.

64. Zhang ZG, Bower L, Zhang RL, Chen S, Windham JP, Chopp M. Three dimensional measurement of cerebral microvascular plasma perfusion, glial fibrillary acid protein and microtubule associated P-2 immunoreactivity after embolic stroke in rats: a double fluorescent labeled laser scanning confocal microscopic study. Brain Res. (1999) 844(1-2): 55-66.

65. Tomimoto H, Akiguchi I, Wakita H, Svenaga T, Nakamura S, Kimura J. Regressive changes of astroglia in white matter lesions in cerebrovascular disease and AD patients. Acta Neuropathol (1997) 94 (2): 146-152.

66. Iadecola C. The pathobiology of vascular dementia. Neuron, 2013; 80: 844-866; O'Brien JT, Thomas A. Vascular dementia. Lancet (2015) 386:1698-1706.

67. Filous AS, Silver J. Targeting astrocytes in CNS injury and disease: a translational research approach. Prog. Neurobiol 2016; 144: 173-187. Doi:10.1016/j.pneurobio.2016.03.009.

68. Chen A, Akinyemi RO, Hase Y, Firbank MJ, Ndung'u MN, Foster V et al.Frontal white matter hyperintensities, clasmatodendrosis and gliovascular abnormalities in ageing and post-stroke dementia. Brain 2016; 139:242-258. https://doi.org/10.1093/brain/awv328.

69. Borovikova LV, Ivanova S, Zhang M, Yang H, Botchkina GI, Watkins LR, et al. Vagus nerve stimulation attenuates the systemic inflammatory response to endotoxin. Nature 2000; 405: 45862.

70. Wang H, Yu M, Ochani M, Amella CA, Tanovic M, Susarla S, et al. Nicotinic acetylcholine receptor alpha7 subunit is an essential regulator of inflammation. Nature 2003; 421: 384-8.

71. Conejero-Goldberg C, Davies P, Ulloa L. Alpha7 nicotinic acetylcholine receptor: a link between inflammation and neurodegeneration. Neurosci Biobehav Rev 2008; 32: 693-706.

72. Pavlov VA, Tracey KJ. Controlling inflammation: the cholinergic anti-inflammatory pathway. Biochem Soc Trans 2006; 34: 1037-40.

73. Kalaria RN, Maestre GE, Arizaga R, Friedland RP, Galasko D, Hall K, Luchsinger JA, Ogunniyi A, Perry EK, Potocnik F, Prince M, Stewart R, Wimo A, Zhang ZX, Antuono P, World Federation of Neurology Dementia Research Group. Alzheimer's disease and vascular dementia in developing countries: prevalence, management, and risk factors. Lancet Neurol. 2008 Sep; 7(9):812-26.

74. Kim HJ, Moon WJ, Han SH. Differential cholinergic pathway involvement in Alzheimer's disease and subcortical ischemic vascular dementia. J Alzheimers Dis. 2013; 35(1):129-36.

75. Kim SH, Kang HS, Kim HJ, Moon Y, Ryu HJ, Kim MY, Han SH. The effect of ischemic cholinergic damage on cognition in patients with subcortical vascular cognitive impairment. J Geriatr Psychiatry Neurol. 2012 Jun; 25(2):122-7.

76. Liu Q, Zhu Z, Teipel SJ, et al. White Matter Damage in the Cholinergic System Contributes to Cognitive Impairment in Subcortical Vascular Cognitive Impairment, No Dementia. Front Aging Neurosci. 2017; 9:47. Published 2017 Feb 27. doi:10.3389/fnagi.2017.00047.

77. Roman GC, Kalaria RN. Vascular determinants of cholinergic deficits in AD and vascular dementia Neurobiol Aging (2006) 27: 1769-1785.

78. Low A, Mak E, Rowe JB, Markus HS, O'Brien JT. Inflammation and cerebral small vessel disease: A systematic review. Ageing Res Rev. 2019;53:100916. doi:10.1016/j.arr.2019.100916

79. Iadecola C, Yang G, Ebner TJ, Chen G. Local and propagated vascular responses evoked by focal synaptic activity in cerebellar cortex. J Neurophysiol (1997) 78(2):651-9.

80. Jung S, Zarow C, Mack WJ, Zheng L, Vinters HV, Ellis WG, et al. Preservation of neurons of the nucleus basalis in subcortical ischemic vascular disease. Arch Neurol (2012) 69:879-886. doi: 10.1001/archneurol.2011.2874.

81. Swartz RH, Sahlas DJ, Black SE. Strategic involvement of cholinergic pathways and executive dysfunction: does location of white matter signal hyperintensities matter? J Stroke Cerebrovasc Dis (2003) 12:29-36.

82. Tong XK, Hamel E. Regional cholinergic denervation of cortical microvessels and nitric oxid synthase-containing neurons in AD. Neuroscience (1999) 92: 163-175. 
83. Cauli B, Tong XK, Rancillac A, Serluca N, lambolez B, Rossier J et al Cortical GABA interneurons in neurovascular coupling: relays for the subcortical vasoactive pathways. J Neurosci (2004) 24: 8940-8949

84. Wardlaw JM, Smith C, Dichgans M. Mechanism of sporadic cerebral small vessel disease: insight from neuroimaging. Lancet Neurol (2013) 12: 483-497.

85. Craggs LJ, Hagel C, Kuhlenbaeumer G, Borjesson-Hanson A, Andersen O, Viitanen M et al (2013) Quantitative vascular pathology and phenotyping familial and sporadic cerebral small vessel diseases. Brain Pathol 23:547-557.

86. Hainsworth AH, Oommen AT, Bridges LR. Endothelial Cells and Human Cerebral Small Vessel Disease. Brain Pathology 25 (2015) 44-50 doi:10.1111/bpa.1222.

87. Frischer JM, Pipp I, Stavrou I, Trattnig S, Hainfellner JA, Knosp E ( 2008) Cerebral cavernous malformations: congruency of histopathological features with the current clinical definition. J Neurol Neurosurg Psychiatry 79:783-788.

88. Giwa MO, Williams J, Elderfield K, Jiwa NS, Bridges LR, Kalaria RN et al (2012) Neuropathologic evidence of endothelial changes in cerebral small vessel disease. Neurology 78:167-174.

89. Zlokovic BV. Neurovascular pathways to neurodegeneration in Alzheimer's disease and other disorders. Nature Reviews Neuroscience, 2011; 12: 723-728.

90. Cai W, Zhang K, Li P, Zhu L, Xu J, Yang B, Hu X, Lu Z, Chen J. Dysfunction of the neurovascular unit in ischemic stroke and neurodegenerative diseases: An aging effect. Ageing Research Reviews, 2017; (34): 77-87,https://doi.org/10.1016/j.arr.2016.09.006.

91. Prisby RD, Ramsey MW, Behnke BJ, Dominguez JM, Donato AJ, Allen MR, Delp MD. Aging reduces skeletal blood flow endothelium dependent vasodilation, and NO bioavailability in Rats. J Bone and Mineral Res. 2007; 22: 1280-1288.

92. Nicholson WT, Vaa B, Hesse C, Eisenach JH, Joyner MJ. Aging is associated with reduced prostacyclin-mediated dilation in the human forearm. Hypertenison, 2009; 53: 973-978.

93. Long DA, Newaz MA, Prabahakar SS, Price KL, Truong L, Feng L, Mu, Oyekan AO, Johnson RJ. Loss of nitric oxide and endothelial-derived hyperpolarizing factor-mediated responses in ageing. Kidney International 2005; 68: 2154-2163.

94. Van der Loo B, Labugger R, Skepper JN, BAchschmid M, Kilo J, Powell JM, Palacios-Callendere M, Erusalimsky JD, Quaschning T, Malinski T. Enhanced peroxynitrite formation is associated with vascular ageing. The Journ Exp.Med. 2000; 192: 1731-1744.

95. Puca AA, Carrizzo A, Ferrario A, Villa F, Vecchione C. Endothelial nitric oxide synthase, vascular integrity and human exceptional longevity.Immunity \&Ageing 2012; 26,9: 1.

96. Flentje A, Kalsi R, Monahan TS. Small GTPases and Their Role in Vascular Disease. Int J Mol Sci. 2019;20(4):917. Published 2019 Feb 20. doi:10.3390/ijms20040917.

97. Hartmann S, Ridley AJ, Lutz S. The Function of Rho-Associated Kinases ROCK1 and ROCK2 in the Pathogenesis of Cardiovascular Disease. Front. Pharmacol. 2015;6:276. doi: 10.3389/fphar.2015.00276.35.

98. Pestonjamasp K, Amieva MR, Strassel CP, Nauseef WM, Furthmayr H, Luna EJ. Moesin, ezrin, and p205 are actin-binding proteins associated with neutrophil plasma membranes. Mol. Biol. Cell. 1995;6:247-259. doi: 10.1091/mbc.6.3.247.

99. Cicek FA, Kandilci HB, Turan B. Role of ROCK upregulation in endothelial and smooth muscle vascular functions in diabetic rat aorta. Cardiovasc. Diabetol. 2013;12:51. doi: 10.1186/1475-284012-51.

100.Noma K, Oyama N, Liao JK. Physiological role of ROCKs in the cardiovascular system. Am. J. Physiol. Cell Physiol. 2006;290:C661-C668. doi: 10.1152/ajpcell.00459.2005.

101.Hassan A, Gormley K, O’Sullivan M, Knight J, Sham P, Vallance P, Bamford J., Markus H Endothelial Nitric Oxide Gene Haplotypes and Risk of Cerebral Small-Vessel Disease. Stroke. 2004;35:654-659.

102. Van Nieuw Amerongen GP, Koolwijk P, Versteilen A, van Hinsbergh VW. Involvement of RhoA/Rho kinase signaling in VEGF-induced endothelial cell migration and angiogenesis in vitro. Arterioscler. Thromb. Vasc. Biol. 2003;23:211-217. doi: 10.1161/01.ATV.0000054198.68894.88. 
103. Matsumoto Y, Uwatoku T, Oi K, Abe K, Hattori T, Morishige K, Eto Y, Fukumoto Y, Nakamura KI, Shibata $\mathrm{Y}$, et al. Long-term inhibition of Rho-kinase suppresses neointimal formation after stent implantation in porcine coronary arteries: Involvement of multiple mechanisms. Arterioscler. Thromb. Vasc. Biol. 2004;24:181-186. doi: 10.1161/01.ATV.0000105053.46994.5B.

104.Szulcek R, Beckers CM, Hodzic J, de Wit J, Chen Z, Grob T, Musters RJ, Minshall RD, van Hinsbergh VW, van Nieuw Amerongen GP. Localized RhoA GTPase activity regulates dynamics of endothelial monolayer integrity. Cardiovasc. Res. 2013;99:471-482. doi: 10.1093/cvr/cvt075.

105. Van Nieuw Amerongen GP, Beckers CM, Achekar ID, Zeeman S, Musters RJ, van Hinsbergh VW. Involvement of Rho kinase in endothelial barrier maintenance. Arterioscler. Thromb. Vasc. Biol. 2007;27:2332-2339. doi: 10.1161/ATVBAHA.107.152322.

106.Wang J, Liu H, Chen B, Li Q, Huang X, Wang L, Guo X, Huang Q. RhoA/ROCK-dependent moesin phosphorylation regulates AGE-induced endothelial cellular response. Cardiovasc. Diabetol. 2012;11:7. doi: 10.1186/1475-2840-11-7.

107.Sun H, Breslin JW, Zhu J, Yuan SY, Wu MH. Rho and ROCK signaling in VEGF-induced microvascular endothelial hyperpermeability. Microcirculation. 2006;13:237-247. doi: 10.1080/10739680600556944.

108. Gradinaru D, Borsa C, Ionescu C, Prada GI, Oxidized LDL and NO synthesis-biomarkers of endothelial dysfunction and ageing. Mechanisms of Ageing and Development. 2015; 151. 101-113.

109.Deplanque D, Lavallee PC, Labreuche J, Gongora-Rivera F, Jaramillo A, Brenner D et al (2013) Cerebral and extracerebral vasoreactivity in symptomatic lacunar stroke patients: a case-control study. Int J Stroke 8:413-421.

110.Gunarathne A, Patel JV, Kausar S, Gammon B, Hughes EA, Lip GY (2009) Glycemic status underlies increased arterial stiffness and impaired endothelial function in migrant South Asian stroke survivors compared to European Caucasians: pathophysiological insights from the West Birmingham Stroke Project. Stroke 40:2298-2306.

111. Markus HS, Lythgoe DJ, Ostegaard L, O'Sullivan M, Williams SC (2000) Reduced cerebral blood flow in white matter in ischaemic leukoaraiosis demonstrated using quantitative exogenous contrast based perfusion MRI. J Neurol Neurosurg Psychiatry 69:48-53.

112. O'Sullivan M, Lythgoe DJ, Pereira AC, Summers PE, Jarosz JM, Williams SC, Markus HS (2002) Patterns of cerebral blood flow reduction in patients with ischemic leukoaraiosis. Neurology 59:321-326.

113.Markus HS, Allan CL, Ebmeier KP (2014) Cerebral hemodynamics in cerebral small vessel disease. In: Cerebral Small Vessel Disease. L Pantoni, PB Gorelick (eds), pp. 180-191. Cambridge University Press: Cambridge.

114.Gallin JI, Snyderman R. Inflammation: Basic Principles and Clinical Correlates, 1999 3rd edn. Lippincott Williams \& Wilkins: Philadelphia.

115.de Leeuw FE, de Kleine M, Frijns CJ, Fijnheer R, van Gijn J, Kappelle LJ. Endothelial cell activation is associated with cerebral white matter lesions in patients with cerebrovascular disease. Ann N Y Acad Sci 2002 977:306-314.

116.Rouhl RP, van Oostenbrugge RJ, Theunissen RO, Knottnerus IL, Staals J, Henskens LH. Autoantibodies against oxidized low-density lipoprotein in cerebral small vessel disease. Stroke 2010 41:2687-2689.

117.Wada M, Takahashi Y, Iseki C, Kawanami T, Daimon M, Kato T. Plasma fibrinogen, global cognitive function, and cerebral small vessel disease: results of a cross-sectional study in community-dwelling Japanese elderly. Intern Med 2011 50:999-1007.

118.Markus HS, Hunt B, Palmer K, Enzinger C, Schmidt H, Schmidt R. Markers of endothelial and hemostatic activation and progression of cerebral white matter hyperintensities: longitudinal results of the Austrian Stroke Prevention Study. Stroke 2005 36:1410-1414.

119.Knottnerus IL, Govers-Riemslag JW, Hamulyak K, Rouhl RP, Staals J, Spronk HM. Endothelial activation in lacunar stroke subtypes. Stroke 2010 41:1617-1622.

120.Knottnerus IL, Cate H, Lodder J, Kessels F, van Oostenbrugge RJ. Endothelial dysfunction in lacunar stroke: a systematic review. Cerebrovasc Dis 2009 27:519-526. 
121.Stevenson SF, Doubal FN, Shuler K, Wardlaw JM. A systematic review of dynamic cerebral and peripheral endothelial function in lacunar stroke versus controls. Stroke 2010 41:e434-e442.

122. Fernando MS, Simpson JE, Matthews F, Brayne C, Lewis CE, Barber R et al. White matter lesions in an unselected cohort of the elderly: molecular pathology suggests origin from chronic hypoperfusion injury. Stroke 2006 37:1391-1398.

123. Esiri MM, Wilcock GK, Morris JH. Neuropathological ssessment of the lesions of significance in vascular dementia. J Neurol Neurosurg Psychiatry 1997 63:749-753.

124.Rajendran P, Rengarajan T, Thangavel J, et al. The vascular endothelium and human diseases. Int J Biol Sci. 2013;9(10):1057-1069. Published 2013 Nov 9. doi:10.7150/ijbs.7502.

125.Drake CT, Iadecola C. The role of the neuronal signaling in controlling cerebral blood flow. Brain Lang. 2007; 102: 141-152.

126.Iadecola C. The pathobiology of vascular dementia. Neuron $2013 ; 80$. http://dx.doi.org/10.1016/j.neuron.2013.10.008.

127.Tallini YN, Brekke JF, Shui B, Doran R, Hwang SM, NAkai J, Salama G, Segal SS, Kotlikoff MI. Propagated endothelial Ca++ waves and arteriolar dilatation in vivo: Measurements in Cx40 BAC GCaMP2 transgenic mice. Circ. Res. 2007; 101: 1300-1309.

128.Segal SS. Integration and modulation of intracellular signaling underlying blood flow control. J. Vasc. Res. 2015; 52: 136-157. Doi: 10.1159/00004391112.

129.Hen BP, Kozberg MG, Bouchard MB, Shaik MA, Hillman EMC. A critical role for the vascular endothelium in functional neurovascular coupling in the brain, J Am. Heart Assoc. 2014; 3 doi: 10.1161/JAHA.114.000787.

130.Longden TA, Hill-Eubanks DC, Nelosn MT. ion channel networks in the control of cerebral blood flow. J Cer blood Flow Metab. 2016; 36: 492-512. Doi: 10.1177/0271678X15616138.

131.Bagher P, Segal SS. Regulation of blood flow in the microcirculation: role of the conducted vasodilation. Acta Physiol. 2011; 202: 271-284. Doi: 10.1111/j.1748-1716.2010.00224.x

132. Uhurovoa H, Kilic K, Tian P, Thunemann M, Desjardins M, et al. Cell-type specificity of neurovascular coupling in cerebral cortex. ELife. 2016: 5: 155. Doi.10.7554/elife.14315.

133.Longden TA, Dabertrand F, Koide M, Gonzales AL, Tykochi NT, Brayden JE, Hill-Eubanks D,Nelosn MT. Capillary $\mathrm{K}+$ sensing initiates retrograde hyperpolarization to increase local cerebral blood flow. Nat Neurosci. 2017: 275: A1489-12.doi.10.1038/nm.4533.

134.Smith, A.D.; Refsum, H. Homocysteine, B vitamins, and cognitive impairment. Annu. Rev. Nutr. 2016, 36, 211-239.

135.Miles, L.; Allen, E.; Mills, K.; Clarke, R.; Uauy, R.; Dangour, A.D. Vitamin B12 status and neurologic function in older people: A cross-sectional analysis of baseline trial data from the Older People and Enhanced Neurological Function (OPEN) study. Am. J. Clin. Nutr. 2016, 104, 790-796.

136.Mudd, S.H.; Cantoni, G.L. Activation of methionine for transmethylation. III. The methionineactivating enzyme of Bakers' yeast. J. Biol. Chem. 1958, 231, 481-492.

137. Mato, J.M.; Alvarez, L.; Ortiz, P.; Pajares, M.A. S-adenosylmethionine synthesis: Molecular mechanisms and clinical implications. Pharmacol. Ther. 1997, 73, 265-280.

138.Blom, H.J.; Smulders, Y. Overview of homocysteine and folate metabolism. With special references to cardiovascular disease and neural tube defects. J. Inherit. Metab. Dis. 2011, 34, 75-81.

139.Loscalzo, J.; Handy, D.E. Epigenetic modifications: Basic mechanisms and role in cardiovascular disease. 2013 Grover Conference Series. Pulm. Circ. 2014, 482, 169-174.

140.Robinson JL, McBreairty LE, Randell EW, et al. Betaine or folate can equally furnish remethylation to methionine and increase transmethylation in methionine-restricted neonates. J Nutr Biochem. 2018;59:129-135. doi:10.1016/j.jnutbio.2018.06.001

141.Kotb, M.; Mudd, S.H.; Mato, J.M. Consensus nomenclature for the mammalian methionine adenosyltransferase genes and gene products. Trends Genet. TIG 1997, 13, 51-52.

142.Fujimori DG. Radical SAM-mediated methylation reactions. Curr Opin Chem Biol. 2013;17(4):597-604. doi:10.1016/j.cbpa.2013.05.032

143.Smulders YM, Blom HJ. The homocysteine controversy. J Inherit Metab Dis. 2011;34(1):93-99. doi:10.1007/s10545-010-9151-1 
144.Parnetti, L.; Bottiglieri, T.; Lowenthal, D. Role of homocysteine in age-related vascular and nonvascular diseases. Aging Clin. Exp. Res. 1997, 9, 241-257.

145. Handy DE, Castro R, Loscalzo J. Epigenetic modifications: basic mechanisms and role in cardiovascular disease. Circulation. 2011;123(19):2145-2156. doi:10.1161/CIRCULATIONAHA.110.956839.

146.Enk, C.; Hougaard, K.; Hippe, E. Reversible dementia and neuropathy associated with folate deficiency 16 years after partial gastrectomy. Scand. J. Haematol. 1980, 25, 63-66.

147. Bottiglieri, T. Ademetionine (S-adenosylmethionine) neuropharmacology: Implications for drug therapies in psychiatric and neurological disorders. Expert Opin. Investig. Drugs 1997, 6, 417-426.

148.Weir, D.G.; Keating, S.; Molloy, A. Methylation deficiency causes vitamin B12-associated neuropathy in the pig. J. Neurochem. 1988, 51, 1949-1952.

149.Surtees, R.; Leonard, J.; Austin, S. Association of demyelination with deficiency of cerebrospinalfluid S-adenosylmethionine in inborn errors of methyl-transfer pathway. Lancet 1991, 338, 1550-1554.

150.Pennypacker, L.C.; Allen, R.H.; Kelly, J.P. High prevalence of cobalamin deficiency in elderly outpatients. J. Am. Geriatr. Soc. 1992, 40, 1197-1204.

151.McKeever, M.P.; Weir, D.G.; Molloy, A.; Scott, J.M. Betaine-homocysteine methyltransferase: Organ distribution in man, pig and rat and subcellular distribution in the rat. Clin. Sci. 1991, 81, 551-556.

152.Leclerc, D.; Wilson, A.; Dumas, R. Cloning and mapping of a cDNA for methionine synthase reductase, a flavoprotein defective in patients with homocystinuria. Proc. Natl. Acad. Sci. USA 1998, 95, 3059-3064.

153.Sunden, S.L.; Renduchintala, M.S.; Park, E.I.; Miklasz, S.D.; Garrow, T.A. Betaine-homocysteine methyltransferase expression in porcine and human tissues and chromosomal localization of the human gene. Arch. Biochem. Biophys. 1997, 345, 171-174.

154.Quéré, I.; Paul, V.; Rouillac, C. Spatial and temporal expression of the cystathionine beta-synthase gene during early human development. Biochem. Biophys. Res. Commun. 1999, 254, 127-137.

155.Obeid, R.; Herrmann, W. Mechanisms of homocysteine neurotoxicity in neurodegenerative diseases with special reference to dementia. FEBS Lett. 2006, 580, 2994-3005.

156.Price, B.R.; Wilcock, D.M.; Weekman, E.M. Hyeprhomocysteinemia as a risk factor for vascular contributions to cognitive impairment and dementia. Front. Aging Neurosci. 2018, 10, 305.

157.Pietrzik, K.; Bronstrup, A. Vitamins B12, B6 and folate as determinants of homocysteine concentration in the healthy population. Eur. J. Pediatr. 1998, 157 (Suppl. 2), S135-S138.

158.Huang, Y.C.; Chang, S.J.; Chiu, Y.T.; Chang, H.H.; Cheng, C.H. The status of plasma homocysteine and related B-vitamins in healthy young vegetarians and nonvegetarians. Eur. J. Nutr. 2003, 42, 8490.

159.Kulkarni, K.; Richard, B.C. Lifestyle, homocysteine and the metabolic syndrome. Metab. Syndr. Relat. Disord. 2003, 1, 141-147.

160. Ansari, R.; Mahta, A.; Mallack, E.; Luo, J.J. Hyperhomocysteinemia and neurologic disorders: A review. J. Clin. Neurol. 2014, 10, 281-288.

161.Stea, T.H.; MAnsoor, M.A.; Wandel, M.; Uglem, S.; Frolich, W. Changes in predictors and status of homocysteine in young male adults after dietary intervention with vegetables, fruits and bread. Eur. J. Nutr. 2008, 47, 201-209.

162.Pushpakumar S, Kundu S, Sen U. Endothelial dysfunction: the link between homocysteine and hydrogen sulfide. Curr Med Chem. 2014;21(32):3662-3672. doi:10.2174/0929867321666140706142335

163.Moretti, R.; Dal Ben, M.; Gazzin, S.; Tiribelli, C. Homcysteine in neurology: From endothelium to neurodegeneration. Curr. Nutr. Food Sci. 2017, 13, 163-175.

164.Surtees, R.; Bowron, A.; Leonard, J. Cerebrospinal fluid and plasma total homocysteine and related metabolites in children with cystathionine beta-synthase deficiency: The effect of treatment. Pediatr. Res. 1997, 42, 577-582.

165.Afman, L.A.; Blom, H.J.; Drittij, M.J.; Brouns, M.R.; van Straaten, H.W. Inhibition of transmethylation disturbs neurulation in chick embryos. Brain Res. Dev. Brain Res. 2005, 158, 59-65.

166.Kamath, A.F.; Chauhan, A.K.; Kisucka, J. Elevated levels of homocysteine compromise blood-brain barrier integrity in mice. Blood 2006, 107, 591-593. 
167.Troen, A.M. The central nervous system in animal models of hyperhomocysteinemia. Prog. NeuroPsychopharmacol. Biol. Psychiatry 2005, 29, 1140-1151.

168.Algaidi, S.A.; Christie, L.A.; Jenkinson, A.M. Long-term homocysteine exposure induces alterations in spatial learning, hippocampal signalling and synaptic plasticity. Exp. Neurol. 2006, 197, 8-21.

169.Ganguly, P.; Alam, S.F. Role of homocysteine in the development of cardiovascular disease. Nutr. J. $2015,14,6$.

170.Omer Sultan M, Farooque U, Javed R, et al. Correlation of Homocysteine Level and Age in Patients with Ischemic Stroke. Cureus. 2020;12(4):e7785. Published 2020 Apr 22. doi:10.7759/cureus.7785.

171. Moretti R, Peinkhofer C. B Vitamins and Fatty Acids: What Do They Share with Small Vessel Disease-Related Dementia?. Int J Mol Sci. 2019;20(22):5797. Published 2019 Nov 18. doi:10.3390/ijms20225797

172. Moretti R. Homocysteine: New Aspects of an Ancient Enigma. Cardiology. 2019;144(1-2):36-39. doi:10.1159/000501997.

173.Piao X, Wu G, Yang P, Shen J, De A, Wu J, Qu Q Association between Homocysteine and Cerebral Small Vessel Disease: A Meta-Analysis. Journal of Stroke and Cerebrovascular Diseases2018; 27 (9): 2423-2430. https://doi.org/10.1016/j.jstrokecerebrovasdis.2018.04.035

174.Rutten-Jacobs LCA, Traylor M, Adib-Samii P, Thijs V, Sudlow C, Rothwell PM, Boncoraglio G, Dichgans M, Meschia J, Maguire J, Levi C, Rost NS, Rosand J, Hassan A, Bevan S, Markus HS. Association of MTHFR C677T Genotype With Ischemic Stroke Is Confined to Cerebral Small Vessel Disease Subtype. Stroke 2016; 47, 3; 646-651 https://doi.org/10.1161/STROKEAHA.115.011545

175.Irizarry, M.C.; Gurol, M.E.; Raju, S. Association of homocysteine with plasma amyloid beta protein in aging and neurodegenerative disease. Neurology 2005, 65, 1402-1408.

176.Hasegawa, T.; Ukai, W.; Jo, D.-G. Homocysteic acid induces intraneuronal accumulation of neurotoxic Abeta42, implications for the pathogenesis of Alzheimer's disease. J. Neurosci. Res. 2005, 80, 869-876.

177.Morris, M.S. Homocysteine and Alzheimer's disease. Lancet Neurol. 2003, 2, 425-428.

178.Kruman, I.I.; Kumaravel, T.S.; Lohani, A. Folic acid deficiency and homocysteine impair DNA repair in hippocampal neurons and sensitize them to amyloid toxicity in experimental models of Alzheimer's disease. J. Neurosci. J. Soc. Neurosci. 2002, 22, 1752-1762.

179.Sai, X.; Kawamura, Y.; Kokame, K. Endoplasmic reticulum stress-inducible protein, Herp, enhances presenilin-mediated generation of amyloid beta-protein. J. Biol. Chem. 2002, 277, 12915-12920.

180.Selkoe, D.J. Presenilin, Notch, and the genesis and treatment of Alzheimer's disease. Proc. Natl. Acad. Sci. USA 2001, 98, 11039-11041.

181.Scarpa, S.; Fuso, A.; D’Anselmi, F.; Cavallaro, R.A. Presenilin 1 gene silencing by Sadenosylmethionine: A treatment for Alzheimer disease? FEBS Lett. 2003, 541, 145-148.

182.Sharma GS, Kumar T, Dar, TA, Singh LR. Protein-N-Homocysteinylation: form cellular toxicity to neurodegeneration. Biochimmica et Biophysica Acta 2015; 1850; 2239-2245. https://doi.org/10.1016/j.bbagen.2015.08.013

183. Leulliot, N.; Quevillon-Cheruel, S.; Sorel, I. Structure of protein phosphatase methyltransferase 1 (PPM1), a leucine carboxyl methyltransferase involved in the regulation of protein phosphatase 2A activity. J. Biol. Chem. 2004, 279, 8351-8358.

184.Ferreira, A.; Lu, Q.; Orecchio, L.; Kosik, K.S. Selective phosphorylation of adult tau isoforms in mature hippocampal neurons exposed to fibrillar A beta. Mol. Cell Neurosci. 1997, 9, 220-234.

185.Wang, J.Z; Gong, C.X.; Zaidi, T.; Grundke-Iqbal, I.; Iqbal, K. Dephosphorylation of Alzheimer paired helical filaments by protein phosphatase-2A and -2B. J. Biol. Chem. 1995, 270, 4854-4860.

186.Vogelsberg-Ragaglia, V.; Schuck, T.; Trojanowski, J.Q.; Lee, V.M. PP2A mRNA expression is quantitatively decreased in Alzheimer's disease hippocampus. Exp. Neurol. 2001, 168, 402-412.

187.Sontag, E.; Hladik, C.; Montgomery, L. Downregulation of protein phosphatase 2A carboxyl methylation and methyltransferase may contribute to Alzheimer disease pathogenesis. J. Neuropathol. Exp. Neurol. 2004, 63, 1080-1091.

188.Zhao, W.-Q.; Feng, C.; Alkon, D.L. Impairment of phosphatase 2A contributes to the prolonged MAP kinase phosphorylation in Alzheimer's disease fibroblasts. Neurobiol. Dis. 2003, 14, 458-469. 
189.Vafai, S.B.; Stock, J.B. Protein phosphatase 2A methylation: A link between elevated plasma homocysteine and Alzheimer's Disease. FEBS Lett. 2002, 518, 1-4.

190.Tolstykh, T.; Lee, J.; Vafai, S.; Stock, J.B. Carboxyl methylation regulates phosphoprotein phosphatase 2A by controlling the association of regulatory B subunits. EMBO J. 2000, 19, 5682-5691.

191.Ho, P.I.; Ashline, D.; Dhitavat, S. Folate deprivation induces neurodegeneration: Roles of oxidative stress and increased homocysteine. Neurobiol. Dis. 2003, 14, 32-42.

192.Wuerthele, S.E.; Yasuda, R.P.; Freed, W.J.; Hoffer, B.J. The effect of local application of homocysteine on neuronal activity in the central nervous system of the rat. Life Sci. 1982, 31, 2683-2691.

193.Lipton, S.A.; Kim, W.K.; Choi, Y.B. Neurotoxicity associated with dual actions of homocysteine at the N-methyl-D-aspartate receptor. Proc. Natl. Acad. Sci. USA 1997, 94, 5923-5928.

194.Ito, S.; Provini, L.; Cherubini, E. L-homocysteic acid mediates synaptic excitation at NMDA receptors in the hippocampus. Neurosci. Lett. 1991, 124, 157-161.

195. Klancnik, J.M.; Cuénod, M.; Gähwiler, B.H.; Jiang, Z.P.; Do, K.Q. Release of endogenous amino acids, including homocysteic acid and cysteine sulphinic acid, from rat hippocampal slices evoked by electrical stimulation of Schaffer collateral-commissural fibres. Neuroscience 1992, 49, 557-570.

196.Kim, J.P.; Koh, J.Y.; Choi, D.W. L-homocysteate is a potent neurotoxin on cultured cortical neurons. Brain Res. 1987, 437, 103-110.

197.Ziemiffska, E.; Stafiej, A.; Lazarewicz, J.W. Role of group I metabotropic glutamate receptors and NMDA receptors in homocysteine-evoked acute neurodegeneration of cultured cerebellar granule neurones. Neurochem. Int. 2003, 43, 481-492.

198.Shi, Q.; Savage, J.E.; Hufeisen, S.J. L-homocysteine sulfinic acid and other acidic homocysteine derivatives are potent and selective metabotropic glutamate receptor agonists. J. Pharmacol. Exp. 2003, 305, 131-142

199.Robert, K.; Pagès, C.; Ledru, A. Regulation of extracellular signal-regulated kinase by homocysteine in hippocampus. Neuroscience 2005, 133, 925-935.

200.De Lau, L.M.; Koudstaal, P.J.; van Meurs, J.B.; Uitterlinden, A.G.; Hofman, A.; Breteler, M.M. Methylenterahydrofolate reductase C677T genotype and PD. Annu. Neurol. 2005, 57, 927-930.

201.Zhao, P.; Yang, J.F.; Liu, W.; Wang, Y.; Sun, Y.N.; Li, Q. Effects of entacapone on plasma homocysteine in Parkinson's Disease patients on levodopoa. Zhongha Yi Xue Za Zhi 2013, 93, 512515.

202.Mok, S.S.; Turner, B.J.; Beyreuther, K. Toxicity of substrate-bound amyloid peptides on vascular smooth muscle cells is enhanced by homocysteine. Eur. J. Biochem. FEBS 2002, 269, 3014-3022.

203.Pang, X.; Liu, J.; Zhao, J.; Mao, J.; Zhang, X.; Feng, L. Homocysteine induces the expression of Creactive protein via NMDAr-ROS-MAPK-NF-KB signal pathway in rat vascular smooth muscle cells. Atherosclerosis 2014, 236, 73-81.

204.Nelson, A.R.; Sweeney, M.D.; Sagare, A.P.; Zlokovic, B.V. Neurovascular dysfunction and neurodegeneration in dementia and Alzheimer's disease. Biochim. Biophys. Acta 2016, 1862, 887-900.

205.Perna, A.F.; Ingrosso, D.; De Santo, N.G. Homocysteine and oxidative stress. Amino Acids 2003, 25, 409-417.

206.Petras, M.; Tatarakova, Z.; Kovalska, M.; Mokra, D.; Dobrota, D.; Lehotsky, J.; Drgova, A. Hyperhomocysteinemia as a risk factor for the neuronal system disorders. J. Physiol. Pharmac 2014, 65, 1-23.

207.Wyse, A.T.S.; Zugno, A.I.; Streck, E.L. Inhibition of $\mathrm{Na}(+), \mathrm{K}(+)$-ATPase activity in hippocampus of rats subjected to acute administration of homocysteine is prevented by vitamins $\mathrm{E}$ and $\mathrm{C}$ treatment. Neurochem. Res. 2002, 27, 1685-1689.

208.Bleie, O.; Semb, A.G.; Grundt, H. Homcysteine-lowering therapy does not affect inflammatory markers of atherosclerosis in patients with stable coronary disease. J. Int. Med. 2007, 262, $244-253$.

209.Ploder, M.; Kurz, K.; Splitter, A.; Neurauter, G.; Roth, E.; Fuch, D. Early increase of plasma Hcy in sepsis patients with poor outcome. Mol. Med. 2010, 16, 498-504.

210.Li, J.-J.; Li, Q.; Du, H.-P. Homocysteine Triggers inflammatory responses in macrophages through inhibiting CSE-H2S signaling via DNA hypermethylation of CSE promoter. Int. J. Mol. Sci. 2015, 16, 12560-12577. 
211.Krishna, S.M.; Dear, A.; Craig, J.M.; Norman, P.E.; Golledge, J. The potential role of homocysteine mediated DNA methylation and associated epigenetic changes in abdominal aortic aneurysm formation. Atherosclerosis 2013, 228, 295-305.

212. Yi-Deng, J.; Tao, S.; Hui-Ping, Z. Folate and ApoE DNA methylation induced by homocysteine in human monocytes. DNA Cell Biol. 2007, 26, 737-744.

213.Chang, P.-Y.; Lu, S.-C.; Lee, C.-M. Homocysteine inhibits arterial endothelial cell growth through transcriptional downregulation of fibroblast growth factor-2 involving $\mathrm{G}$ protein and DNA methylation. Circ. Res. 2008, 102, 933-941.

214.Kamat PK, Kalani A, Givvimani S, Sathnur PB, Tyagi SC, Tyagi N (2013). Hydrogen sulfide attenuates neurodegeneration and neurovascular dysfunction induced by intracerebraladministered homocysteine in mice. Neuroscience 252: 302-319.

215.Han S, Wu H, Li W, Gao P (2015). Protective effects of genistein in homocysteine-induced endothelial cell inflammatory injury. Mol Cell Biochem 403: 43-49.

216.Li J, Luo M, Xie N, Wang J, Chen L (2016). Curcumin protects endothelial cells against homocysteine induced injury through inhibiting inflammation. Am J Transl Res 8: 4598-4604.

217.Keegan PM, Wilder CL, Platt MO (2012). Tumor necrosis factor alpha stimulates cathepsin K and V activity via juxtacrine monocyteendothelial cell signaling and JNK activation. Mol Cell Biochem 367: 65-72.

218. Li X, Cheng XW, Hu L, Wu H, Guo-Ping, Hao CN et al. (2015). Cathepsin S activity controls ischemia-induced neovascularization in mice. Int J Cardiol 183: 198-208.

219.Zhou J, Zhang YY, Li QY, Cai ZH (2015). Evolutionary history of cathepsin L (L-like) family genes in vertebrates. Int J Biol Sci 11: 1016-1025

220.Pribis JP, Al-Abed Y, Yang H, Gero D, Xu H, Montenegro MF et al. (2015). The HIV protease inhibitor saquinavir inhibits HMGB1 driven inflammation by targeting the interaction of cathepsin V with TLR4/MyD88. Mol Med . https://doi.org/10.2119/ molmed.2015.00197.

221.Reichenbach G, Starzinski-Powitz A, Sloane BF, Doll M, Kippenberger S, Bernd A et al. (2013). PPAR $\alpha$ agonist Wy14643 suppresses cathepsin B in human endothelial cells via transcriptional, posttranscriptional and post-translational mechanisms. Angiogenesis 16: 223-233.

222.Platt MO, Shockey WA (2016). Endothelial cells and cathepsins: biochemical and biomechanical regulation. Biochimie 122: 314-323.

223.Du X, Chen NL, Wong A, Craik CS, Brömme D (2013). Elastin degradation by cathepsin V requires two exosites. J Biol Chem 288: 34871-34881.

224.Leng YP, Ma YS, Li XG, et al. 1-Homocysteine-induced cathepsin V mediates the vascular endothelial inflammation in hyperhomocysteinaemia. Br J Pharmacol. 2018;175(8):1157-1172. doi:10.1111/bph.13920

225. Ahmad S, Siddiqi MI. Insights from molecular modeling into the selective inhibition of cathepsin $S$ by its inhibitor. J Mol Model. 2017;23(3):92. doi:10.1007/s00894-017-3255-6

226. Aavik E, Lumivuori H, Leppänen O, Wirth T, Häkkinen SK, Bräsen JH et al. (2015). Global DNA methylation analysis of human atherosclerotic plaques reveals extensive genomic hypomethylation and reactivation at imprinted locus 14q32 involving induction of a miRNA cluster. Eur Heart J 36: 993-1000.

227.Deng, J.; Lu, S.; Li, H. Homocysteine activates B cells via regulating PKM-2 dependent metabolic reprogramming. J. Immunol. 2017, 198, 170-183.

228.Boldyrev, A.; Bryshkova, E.; MAshkina, A.; Vladychenskaya, E. Why is homocysteine toxic for the nervous and immune systems? Curr. Aging Sci. 2013, 6, 29-36.

229.Essouma, M.; Noubiap, J.J.N. Therapeutic potential of folic acid supplementation for cardiovascular disease prevention through homocysteine lowering and blockade in rheumatoid arthritis patients. Biomark. Res. 2015, 3, 24.

230.Ying, G.; Wang, Y.; Cen, X.M.; Yang, M.; Liang, Y.; Xie, Q.B. Lipid peroxidation-mediated inflammation promotes cell apoptosis through activation of NFK-B pathway in rheumatoid arthritis synovial cells. Med. Infalmm. 2015, 2015, 1-10. 
231.Antoniades, C.; Tousoulis, D.; Marinou, K. Asymmetrical dimethylarginine regulates endothelial function in methionine-induced but not in chronic homocystinemia in humans: Effect of oxidative stress and proinflammatory cytokines. Am. J. Clin. Nutr. 2006, 84, 781-788.

232.Schwedhelm, E.; Xanthakis, V.; Maas, R. Asymmetric dimethylarginine reference intervals determined with liquid chromatography-tandem mass spectrometry: Results from the Framingham offspring cohort. Clin. Chem. 2009, 55, 1539-1545.

233.Li, Z.; Sun, L.; Zhang, H. Elevated plasma homocysteine was associated with hemorrhagic and ischemic stroke, but methylenetetrahydrofolate reductase gene c677t polymorphism was a risk factor for thrombotic stroke a multicenter case-control study in China. Stroke 2003, 34, 2085-2090.

234.Kumar A, Palfrey HA, Pathak R, Kadowitz PJ, Gettys TW, Murthy SN. The metabolism and significance of homocysteine in nutrition and health. Nutr Metab (Lond). 2017;14:78. Published 2017 Dec 22. doi:10.1186/s12986-017-0233-z

235.Li JG, Chu J, Barrero C, Merali S, Praticò D. Homocysteine exacerbates $\beta$-amyloid pathology, tau pathology, and cognitive deficit in a mouse model of Alzheimer disease with plaques and tangles. Ann Neurol. 2014;75:851-863.

236. Vallance P, Leiper J. Cardiovascular biology of the asymmetric dimethylarginine: dimethylarginine dimethylaminohydrolase pathway. Arterioscler Thromb Vasc Biol. 2004;24:1023-1030.

237.Lentz SR, Rodionov RN, Dayal S. Hyperhomocysteinemia, endothelial dysfunction, and cardiovascular risk: the potential role of ADMA. Atheroscler Suppl. 2003;4:61-65.

238.Dayal S, Lentz SR. ADMA and hyperhomocysteinemia. Vasc Med. 2005;10:S27-S33.

239. Low A, Mak E, Rowe JB, Markus HS, O'Brien JT. Inflammation and cerebral small vessel disease: A systematic review.-Ageing Res Rev. 2019;53:100916. doi:10.1016/j.arr.2019.100916

240.Hassan A, Hunt BJ, O'Sullivan M et al. Homocysteine is a risk factor for cerebralr small vessel disease, acting via endothelial dysfunction. Brain 2004; 127: 212-219.

241.Schroder M, Kaufman RJ: ER stress and the unfolded protein response. Mutat Res 2005; 569:29-63.

242. Walter P, Ron D: The unfolded protein response: from stress pathway to homeostatic regulation. Science 2011;334:1081-1086.

243.Lai WK, Kan MY. Homocysteine-Induced Endothelial Dysfunction. Ann Nutr Metab. 2015;67(1):1-12. doi:10.1159/000437098

244.Tian X, Zhao L, ong X. Et al. HSP27 inhibits homocysteien-induced endothelial apoptosis by modulation of ROS production and mithocondrial caspase-depndent apoptotic pathway. Biomed Res. Int. 2016; 4847874.

245.Hossain GS, van Thienen JV, Werstuck GH, Zhou J, Sood SK, Dickhout JG, de Koning AB, Tang D, Wu D, Falk E, Poddar R, Jacobsen DW, Zhang K, Kaufman RJ, Austin RC: TDAG51 is induced by homocysteine, promotes detachment-mediated programmed cell death, and contributes to the development of atherosclerosis in hyperhomocysteinemia. J Biol Chem 2003; 278: 30317-30327.

246.Jakubowski H: Homocysteine thiolactone: metabolic origin and protein homocysteinylation in humans. J Nutr 2000;130(2S suppl): 377S-381S.

247.Perla-Kajan J, Twardowski T, Jakubowski H: Mechanisms of homocysteine toxicity in humans. Amino Acids 2007;32:561-572.

248.Jakubowski H: The pathophysiological hypothesis of homocysteine thiolactone-mediated vascular disease. J Physiol Pharmacol 2008;59(suppl 9):155-167.

249.Frey D, Braun O, Briand C, Vasak M, Grutter MG: Structure of the mammalian NOS regulator dimethylarginine dimethylaminohydrolase: a basis for the design of specific inhibitors. Structure 2006;14:901-911.

250.Mercie P, Garnier O, Lascoste L, Renard M, Closse C, Durrieu F, Marit G, Boisseau RM, Belloc F: Homocysteine-thiolactone induces caspase-independent vascular endothelial cell death with apoptotic features. Apoptosis 2000;5:403-411

251.Dayal S, Wilson KM, Leo L, Arning E, Bottiglieri T, Lentz SR: Enhanced susceptibility to arterial thrombosis in a murine model of hyperhomocysteinemia. Blood 2006;108:2237-2243.

252.Undas A, Brozek J, Szczeklik A: Homocysteine and thrombosis: from basic science to clinical evidence. Thromb Haemost 2005;94: 907-915. 
253.Sauls DL, Lockhart E, Warren ME, Lenkowski A, Wilhelm SE, Hoffman M: Modification of fibrinogen by homocysteine thiolactone increases resistance to fibrinolysis: a potential mechanism of the thrombotic tendency in hyperhomocysteinemia. Biochemistry 2006;45: 2480-2487.

254.Tamura Y, Inoue A, Ijiri Y, Naemura A, Yamamoto J: Short- and long-term treatment with folic acid suppresses thrombus formation in atherogenic mice in vivo. Pathophysiology 2014;21:169-175.

255.Hofmann MA, Lalla E, Lu Y, Gleason MR, Wolf BM, Tanji N, Ferran LJ Jr, Kohl B, Rao V, Kisiel W, Stern DM, Schmidt AM: Hyperhomocysteinemia enhances vascular inflammation and accelerates atherosclerosis in a murine model. J Clin Invest 2001;107:675- 683.

256.Pang X, Liu J, Li Y, Zhao J, Zhang X. Emodin Inhibits Homocysteine-Induced C-Reactive Protein Generation in Vascular Smooth Muscle Cells by Regulating PPAR $\gamma$ Expression and ROS-ERK1/2/p38 Signal Pathway. PLoS One. 2015;10(7):e0131295. Published 2015 Jul 1. doi:10.1371/journal.pone.0131295.

257.Reddy VS, Trinath J, Reddy GB. Implication of homocysteine in protein quality control processes. Biochimie. 2019;165:19-31. doi:10.1016/j.biochi.2019.06.017.

258.Ai, Y.; Sun, Z.; Peng, C.; Liu, L.; Xiao, X.; Li, J. Homocysteine Induces Hepatic Steatosis Involving ER Stress Response in High Methionine Diet-Fed Mice. Nutrients 2017, 9, 346.

259. Yakub, M., Schulze, K. J., Khatry, S. K., Stewart, C. P., Christian, P., \& West, K. P. (2014). High plasma homocysteine increases risk of metabolic syndrome in 6 to 8 year old children in rural Nepal. Nutrients, 6(4), 1649-1661. https://doi.org/10.3390/nu6041649.

260.Zheng X, Xu F, Liang H, et al. SIRT1/HSF1/HSP pathway is essential for exenatide-alleviated, lipidinduced hepatic endoplasmic reticulum stress. Hepatology. 2017;66(3):809-824. doi:10.1002/hep.29238.

261.Chen S, Dong Z, Cheng M, et al. Homocysteine exaggerates microglia activation and neuroinflammation through microglia localized STAT3 overactivation following ischemic stroke. J Neuroinflammation. 2017;14(1):187. Published 2017 Sep 18. doi:10.1186/s12974-017-0963-x

262.Raible DJ, Frey LC, Brooks-Kayal AR. Effects of JAK2-STAT3 signaling after cerebral insults. JAKSTAT. 2014;3:e29510.

263.Liang Z, Wu G, Fan C, Xu J, Jiang S, Yan X, Di S, Ma Z, Hu W, Yang Y. The emerging role of signal transducer and activator of transcription 3 in cerebral ischemic and hemorrhagic stroke. Prog Neurobiol. 2016;137:1-16.

264.Zhu H, Zou L, Tian J, Du G, Gao Y. SMND-309, a novel derivative of salvianolic acid B, protects rat brains ischemia and reperfusion injury by targeting the JAK2/STAT3 pathway. Eur J Pharmacol. 2013;714:23-31.

265.Satriotomo I, Bowen KK, Vemuganti R. JAK2 and STAT3 activation contributes to neuronal damage following transient focal cerebral ischemia. J Neurochem. 2006;98:1353-68.

266. Yi JH, Park SW, Kapadia R, Vemuganti R. Role of transcription factors in mediating post-ischemic cerebral inflammation and brain damage. Neurochem Int. 2007;50:1014-27.

267.Probert L, Akassoglou K, Pasparakis M, Kontogeorgos G, Kollias G. Spontaneous inflammatory demyelinating disease in transgenic mice showing central nervous system-specific expression of tumor necrosis factor alpha. Proc Natl Acad Sci U S A. 1995;92:11294-8.

268.Wu X, Zhang L, Miao Y, et al. Homocysteine causes vascular endothelial dysfunction by disrupting endoplasmic reticulum redox homeostasis. Redox Biol. 2019;20:46-59. doi:10.1016/j.redox.2018.09.021

269.Ji C, Kaplowitz N (2004). Hyperhomocysteinemia, endoplasmic reticulum stress, and alcoholic liver injury. World J Gastroenterol 10:1699-1708.

270.Hohsfeld LA, Humpel C (2010) Homocysteine enhances transmigration of rat monocytes through a brain capillary endothelial cell monolayer via ICAM-1. Curr Neurovasc Res 7:192-200.

271.Gutteridge JM, Halliwell B. Antioxidants: molecules, medicines, and myths. Biochem Biophys Res Commun 2010; 393: 561-564.

272.Thampi P, Stewart BW, Joseph L, Melnyk SB, Hennings LJ and Nagarajan S: Dietary homocysteine promotes atherosclerosis in apoE-deficient mice by inducing scavenger receptors expression. Atherosclerosis 197: 620-629, 2008. 
273.Postea O, Krotz F, Henger A, Keller C, Weiss N. Stereospecific and redox-sensitive increase in monocyte adhesion to endothelial cells by homocysteine. Arterioscler Thromb Vasc Biol 2006; 26: 508-513

274. Vegeto E, Bonincontro C, Pollio G et al (2001) Estrogen prevents the lipopolysaccharide-induced infammatory response in microglia. J Neurosci 21:1809-1818.

275.Zou CG, Zhao YS, Gao SY et al (2010) Homocysteine promotes proliferation and activation of microglia. Neurobiol Aging 31:2069-2079. https://doi.org/10.1016/j.neurobiolaging.2008.11.007.

276.Skovierova H, Vidomanova E, Mahmood S, Sopkova J, Drgova A, Cervenova Tet al. (2016). The molecular and cellular effect of homocysteine metabolism imbalance on human health. Int J Mol Sci 17: 1733.

277.Sheng-Chao Ma, Yin-Ju Hao, Yun Jiao, Yan-Hua Wang, Ling-Bo Xu, Cai-Yan Mao, Xiao-Ling Yang, An-Ning Yang, Jue Tian, Ming-Hao Zhang, Shao-Ju Jin, Hua Xu, Yi-Deng Jiang and Hui-Ping Zhang. Homocysteine-induced oxidative stress through TLR4/NF- $\kappa$ B/DNMT1-mediated LOX-1 DNA methylation in endothelial cells. MOLECULAR MEDICINE REPORTS, 2017: 16: 9181-9188.

278. Jellinger, K.A. Pathology and pathogenesis of vascular cognitive impairment-a critical update. Front. Aging Neurosci. 2013, 5, 17-46.

279.Ignarro, L.J.; Buga, G.M.; Wood, K.S.; Byrns, R.E.; Chaudhuri, G. Endothelium-derived relaxing factor produced and released from artery and vein is nitric oxide. Proc. Natl. Acad. Sci. USA 1987, 84, 9265-9269.

280.Flaubert Tchantchou, Molly Goodfellow, Fengying Li, Lyric Ramsue, Catriona Miller, Adam Puche, Gary Fiskum. Hyperhomocysteinemia-Induced Oxidative Stress Exacerbates Cortical Traumatic Brain Injury Outcomes in Rats. Cellular and Molecular Neurobiology 2020 https://doi.org/10.1007/s10571-020-00866-7.

281.Hoffman, M. Hypothesis: Hyperhomocysteinemia is an indicator of oxidant stress. Med Hypotheses 2011, 77, 1088-1093.

282.Sen, U.; Mishra, P.K.; Tyagi, N.; Tyagi, S.C. Homocysteine to hydrogen sulfide or hypertension. Cell Biochem. Biophys. 2010, 57, 49-58.

283.Sawle, P.; Foresti, R.; Green, C.J.; Motterlini, R. Homocysteine attenuates endothelial hemeoxygenase-1 induction by nitric oxide (NO) and hypoxia. FEBS Lett. 2001, 508, 403-406.

284.Stuhlinger, M.C.; Tsao, P.S.; Her, J.H.; Kimoto, M.; Balint, R.F.; Cooke, J.P. Homocysteine impairs the nitric oxide synthase pathway: Role of asymmetric dimethylarginine. Circulation 2001, 104, 25692575.

285.Vallance, P.; Chan, N. Endothelial function and nitric oxide: Clinical relevance. Heart 2001, 85, 342350.

286.Tyagi N et al (2005) Mechanisms of homocysteine-induced oxidative stress. Am J Physiol-Heart Circ Physiol 289(6):H2649-H2656.

287.Fornier, I.; Ploye, F.; cottet-Emard, J.M.; Brun, J.; Claustrat, B. Folate deficiency alters melatonin secretion in rats. J. Nutr. 2022, 132, 2781-2784.

288.Reiter, R.J.; Tan, D.X.; Pappolla, M.A. Melatonin relieves the neural oxidative burden tht contributes to dementias. Annu. NY Acad. Sci. 2004, 1035, 179-196.

289.Baydar, G.; Ozer, M.; Yasar, A.; tuzcu, M.; Koz, S.T. Melatonin improves learning and memory performances impaired by hyperhomocysteinemia in rats. Brain Res. 2005, 1046, 187-194.

290.Baydar, G.; Kutlu, S.; Nazirroglu, M.; Canpolat, S.; Sandal, S.; Ozcan, M.; Kelestimur, H. Inhibitory effects of melatonin on neural lipid peroxidation induced by intracerebroventricularly administered homocysteine. J. Pinel. Res. 2003, 34, 36-39.

291.Curro, M.; Gugliandolo, A.; Gangemi, C.; Risitano, R.; Ientile, R.; Caccamo, D. Toxic effects of mildy elevated homocysteine concnetrations in neuronal-like cells. Neurochem. Res. 2014, 39, 1485-1495.

292.Sharma, M.; Rai, S.K.; Tiwari, M.; Chandra, R. Effect of hyperhomcysteinemia on cardiovascular risk factors and initiation of atherosclerosis in Wistar rats. Eur. J. Pharamcol. 2007, 574, 49-609

293.Zou, C.-G.; Banerjee, R. Homocysteine and redox signaling. Antioxid. Redox. Signal. 2005, 7, 547-559.

294.Banerjee, R.; Zou, C.-G. Redox regulation and reaction mechanism of human cystathionine-betasynthase: A PLP-dependent hemesensor protein. Arch. Biochem. Biophys. 2005, 433, 144-156. 
295.James, S.J.; Cutler, P.; Melnyk, S. Metabolic biomarkers of increased oxidative stress and impaired methylation capacity in children with autism. Am. J. Clin. Nutr. 2004, 80, 1611-1617.

296.Prudova, A.; Bauman, Z.; Braun, A. S-adenosylmethionine stabilizes cystathionine beta-synthase and modulates redox capacity. Proc. Natl. Acad. Sci. USA 2006, 103, 6489-6494.

297.Reis, E.A.; Zugno, A.I.; Franzon, R. Pretreatment with vitamins E and C prevent the impairment of memory caused by homocysteine administration in rats. Metab. Brain Dis. 2002, 17, 211-217.

298.Murr, C.; Widner, B.; Wirleeitner, B.; Fuchs, D. Neopterin as a marker for immune system activation. Curr Drug Metab. 2001, 2, 175-187.

299.Gurkan Aykutoglu, Musa Tartik, Ekrem Darendelioglu, Adnan Ayna, Giyasettin Baydas. Melatonin and vitamin E alleviate homocysteine-induced oxidative injury and apoptosis in endothelial cells. Molecular Biology Reports 2020 https://doi.org/10.1007/s11033-020-05607-z

300.Kumar D, Jugdutt BI (2003) Apoptosis, and oxidants in the heart.J Lab Clin Med 142:5-8.

301. Tartik M, Darendelioglu E, Aykutoglu G, Baydas G (2016) Turkish propolis supresses MCF-7 cell death induced by homocysteine. Biomed Pharmacother 82:704-712. 